\title{
WestVirginiaUniversity
}

THE RESEARCH REPOSITORY @ WVU

Graduate Theses, Dissertations, and Problem Reports

2004

\section{Three essays on spatial spillovers of highway investment and regional growth}

\author{
Samia Islam \\ West Virginia University
}

Follow this and additional works at: https://researchrepository.wvu.edu/etd

\section{Recommended Citation}

Islam, Samia, "Three essays on spatial spillovers of highway investment and regional growth" (2004). Graduate Theses, Dissertations, and Problem Reports. 2114.

https://researchrepository.wvu.edu/etd/2114

This Dissertation is protected by copyright and/or related rights. It has been brought to you by the The Research Repository @ WVU with permission from the rights-holder(s). You are free to use this Dissertation in any way that is permitted by the copyright and related rights legislation that applies to your use. For other uses you must obtain permission from the rights-holder(s) directly, unless additional rights are indicated by a Creative Commons license in the record and/ or on the work itself. This Dissertation has been accepted for inclusion in WVU Graduate Theses, Dissertations, and Problem Reports collection by an authorized administrator of The Research Repository @ WVU.

For more information, please contact researchrepository@mail.wvu.edu. 
Three Essays on Spatial Spillovers of Highway Investment and Regional Growth

\author{
Samia Islam \\ Dissertation submitted to the \\ College of Business and Economics \\ at West Virginia University \\ in partial fulfillment of the requirements \\ for the degree of
}

Doctor of Philosophy

in

Economics

Brian J. Cushing, Ph.D., Chair

David R. Martinelli, Ph.D.

Timothy T. Phipps, Ph.D.

Santiago M. Pinto, Ph.D.

Peter V. Schaeffer, Ph.D.

Russell S. Sobel, Ph.D.

Division of Economics and Finance

Morgantown, West Virginia

2004

Keywords: Spatial Spillovers, Highway Capital, Regional Growth

c) Copyright 2004, Samia Islam 


\section{ABSTRACT \\ Three Essays on Spatial Spillovers of Highway Investment and Regional Growth}

\section{Samia Islam}

The impact of transportation infrastructure on regional employment can be reflected through changes in the accessibility of the region affected. A certain region may benefit from the positive externalities associated with a public works project even though the facilities are located in another region. The extent of these spillovers can be determined by using a measure of proximity to highway infrastructure in a model of employment. The first essay in this dissertation examines the distance decay in employment growth and the spatial spillovers of highway investment in the 411-county Appalachian region. Although distance decay in employment is not evident after applying the appropriate spatial model, I do find evidence of substantial spatial spillovers of employment across the region's counties.

In my second essay, I estimate the spatial spillovers of public capital investment in highways on regional output within a production function framework. This essay presents an elaboration of the spatial model selection and estimation methods. The last section of the paper examines the direction of causality between output and highway capital stock using spatial autoregressive models and finds evidence of causation from highway capital stock to output but not vice versa.

Given the wide economic gaps characterizing Appalachian counties, it is also important to examine whether disparate areas respond differently to the same policy interventions and development stimulus. In my third essay I address this question. The Appalachian Regional Commission divides the 411 regional counties into four major categories: 'distressed', 'transitional', 'competitive', and 'attainment'. This essay applies spatial models that account for spatial interdependence to evaluate the impact of Appalachian highways on economically disparate counties. Using a spatial autoregressive model in a production function framework, I find that distressed counties gain from highways whereas competitive counties actually suffer from a backwash effect that tends to draw productive activity away from these counties into neighboring counties. 


\section{Table of Contents}

Abstract

List of Tables and Figures

Acknowledgments

Chapter 1: Introduction, Brief Overview of Appalachian Region and Dissertation Outline

1.1 Introduction $\ldots 2$

1.2 A Brief Overview of the Appalachian Region $\ldots 3$

1.3 Dissertation Outline _..6

Chapter 2: Distance Decay in the Impact of Highway Access and Spatial Spillovers of Employment in Appalachia $\quad \ldots 10$

2.1 Introduction $\quad \ldots 12$

2.2. General Objective $\ldots 14$

2.3. Literature

2.3.1. Highway Investment $\quad \ldots 16$

2.3.2. Spatial Spillovers $\quad \ldots 19$

2.4. Methodology and Data $\ldots 21$

2.5 Results $\ldots 24$

2.6 Conclusion $\ldots 29$

Tables and Figures $\quad \ldots 32$

References $\quad \ldots 39$

Chapter 3: The Effect of Highway Capital on Output in Appalachia: Application of Spatial Autoregressive Models in Causality Analysis

3.1 Introduction $\ldots 49$

3.2 Literature Review $\ldots 50$

3.3 Methodology $\ldots 53$

3.4 Data $\ldots 54$

3.5 Spatial Model Specification $\quad \ldots 57$

3.6 Model Selection $\quad \ldots 59$

3.7 Direction of Causation $\ldots 62$

3.8 Results $\quad \ldots 64$

3.9 Conclusion $\quad \ldots 68$

Tables $\quad \ldots 71$

References $\quad \ldots 74$

Chapter 4: An Examination of the Differential Impact of Highway Capital Investment on Economically Disparate Appalachian Counties

4.1 Introduction 
4.2 Methodology and Data $\ldots 83$

4.3 Results $\quad \ldots 86$

4.4 Conclusion $\quad \ldots 90$

Tables $\quad \ldots 93$

Appendix $\quad \ldots 99$

References $\quad \ldots 103$

Chapter 5: Summary and Conclusion $\quad$..106

5.1 Concluding Remarks and Future Research _..107 


\section{List of Tables and Figures}

\section{Tables}

Table 2.1: $\quad$ List of Explanatory Variables $\quad$..32

Table 2.2: $\quad$ OLS Regression Results _..33

Table 2.3: $\quad$ Spatial Lag Model - Maximum Likelihood Estimation _..34

Table 3.1: $\quad$ Impact of Highway Capital on County Output in Appalachia: Spatial Model Estimation Results Using 1992 and 1987 Data $\quad . .71$

Table 3.2: $\quad$ Examining the Direction of Causation between Highway Capital and County Output: An Application of SAR Analysis $\quad . .72$

Table 3.3: Determining the Effect of Highway Capital on Total Public Capital $\quad$...73

Table 4.1: $\quad$ Output in Distressed Counties - SAR analysis $\quad \ldots 93$

Table 4.2: $\quad$ Output in Transitional Counties - SAR Analysis $\quad$..94

Table 4.3: $\quad$ Output in Competitive Counties - SAR Analysis $\quad . .95$

Table 4.4: $\quad$ Output in Competitive Counties - OLS Results ‥96

Table 4.5: $\quad$ Output in Distressed Counties - OLS results $\quad \ldots 97$

Table 4.6: $\quad$ Output in Transitional Counties- OLS Results $\quad$..98

Table 4.7: Counties Designated as 'Attainment and Competitive' by the Appalachian Regional Commission (ARC), $2000 \quad$..999

Table 4.8: Counties Designated as 'Transitional' by the ARC, $2000 \quad \ldots 100$

Table 4.9: C Counties Designated as 'Distressed’ by the ARC, $2000 \quad \ldots 102$

\section{Figures}

Figure 1 A Map of the Appalachian Region $\quad$..6

Figure 2.1: Share of Sector-wise Final Demand in GDP _..35

Figure 2.2: Total Government Spending on Transportation, 1985-1999 ‥36

Figure 2.3: Mapping the OLS Residuals of Employment Growth ‥37

Figure 2.4: $\quad$ Mapping the Residuals of Employment Growth from the Spatial Lag Model 


\section{Acknowledgments}

I would like to thank Dr. Brian Cushing for his unwavering support, encouragement and understanding over the past five years. I am forever indebted to him for his time, patience, and wisdom. In times of trouble and confusion, his assurances were a source of strength and optimism for me. I would also like to thank Dr. Santiago Pinto and Dr. Tim Phipps for always being there to help me in times of crisis with insightful comments and constant encouragement. I extend my gratitude to Dr. David Martinelli, Dr. Peter Schaeffer and Dr. Russell Sobel for their thoughtful advice and comments. I am grateful to Dr. Randall Jackson, Dr. Yasuhide Okuyama and Dr. George Hammond for giving me the opportunity to learn from them. Special thanks to Dr. James LeSage for his many helpful suggestions as well as for the MATLAB toolbox, which is an invaluable resource for economists, and to Dr. Greg Bischak and Keith Witt for their help with the Appalachian data. Thanks to Dr. Hossain Zillur Rahman of PPRC, Bangladesh, without whom my education abroad would not have been possible, and to Dr. S. M. Ashiquzzaman of Dhaka University, Bangladesh, for believing in me. Special thanks to my childhood mentor Sadi Abdullah who introduced me to the possibilities of Economics. Last but not least, I would like to thank my sister Farah for always being there to listen to me whine and laughing at my jokes even when they are not quite funny.

The standard disclaimers apply. 
To my grandfather, A.K.M. Kamaruddin Ahmad, who taught me never to quit without trying. 


\section{Chapter 1}

Introduction, Brief Overview of Appalachian Region and Dissertation Outline 


\subsection{Introduction}

This dissertation presents a geospatial analysis of the impact of highway infrastructure and highway capital investment on the Appalachian Region. Appalachian counties are not homogeneous in any respect, save the hilly terrain that characterizes the region. While a small number of the 411 counties have performed well over the last four decades, a majority of the region's counties have failed to perform up to par. Regional policy makers have taken many initiatives to provide economic stimuli to these backward areas. Some measures have worked better than others. The most costly intervention has undoubtedly been the Appalachian Development Highway System (ADHS).

Highways increase connectivity between places, enhancing accessibility for both labor and capital, which can eventually translate into regional economic growth. Public capital is the primary source of funding for highway infrastructure development. During the 1985 to 1999 period, highways comprised almost two-thirds (61 percent, on average) of total government transportation spending. In 2000, the accumulated public capital stock in highways and streets was valued at \$1.4 trillion (current dollars). From 1988 to 2000, the value (in chained 1996 dollars) of highway capital stock increased by 25 percent (TSAR 2001 $\left.{ }^{1}\right)$.

In evaluating regional impact of any public project, the role of space is crucial because all economic activity occurs in space, which is continuous. Development in a particular area, therefore, is likely to cause positive and/or negative externalities for its neighbors. Geographers have long been concerned about such spatial interdependence but only recently has space enjoyed similar attention in economic analysis.

1 Transportation Statistics Annual Report (2001), Bureau of Transportation Statistics, U.S. Department of Transportation, Washington D.C. 
Regional analyses of the economic impact of highway infrastructure projects have often not accounted for the presence of spatial interdependence among geographically proximate areas. The few studies that have looked into spatial spillovers of highways presented varying estimates of spillovers ranging anywhere from positive to negative. Some have found cross-state positive spillovers of highway capital. In most cases, once spillovers are accounted for, the coefficient of public capital turns out to be higher. Unlike the studies that looked at spatial spillovers at the state level, this dissertation looks at spillovers at the county level. A generalized look at the 13 states does not truly capture the differences among them. The smaller the geographic unit of analysis, the easier it is to understand the actual impact of the highway system on Appalachia's widely disparate composite areas. An overview of the Appalachian region is presented in Section 1.2 below.

\subsection{A Brief Overview of Appalachian Region}

Appalachia, a 200,000-square-mile region, follows the spine of the Appalachian Mountains from southern New York to northern Mississippi. About 23 million people live in the 410 counties of the Appalachian Region. About 42 percent of the region's population is rural, compared with 20 percent of the national population.

The region comprises counties from 13 eastern and southern states. Only West Virginia falls wholly within the region. The other 12 states include Alabama (37 counties), Georgia (37 counties), Kentucky (51 counties), Maryland (3 counties), Mississippi (24 counties), New York (14 counties), North Carolina (24 counties), Ohio 
(29 counties), Pennsylvania (52 counties), Tennessee (50 counties), and Virginia (23 counties, plus 7 independent cities).

In the past, the region's economy relied heavily on natural resource extraction and manufacturing. Lately, the region has diversified, with a higher emphasis on services and widespread development of tourism, especially in more remote areas with no other viable industry. Coal remains an important resource, but the coal industry is not a major provider of jobs.

According to the Appalachian Regional Commission website (ARC 2003²), one of every three Appalachians lived in poverty in the 1950s. High unemployment and harsh living conditions had forced more than 2 million Appalachians to leave their homes and seek work in other regions by the mid 1960s. Given the growing economic despair, and at the urging of two U.S. presidents, Congress created legislation to address Appalachia's persistent poverty and isolation.

The President's Appalachian Regional Commission's (PARC) findings and recommendations formed the basis for the Appalachian Regional Development Act (ARDA), signed into law on March 9, 1965. Second on the commission's agenda as defined by the act is to: “...provide the major portion of funding for a regional highway system to alleviate the Region's isolation” (ARC 2003).

The base for ARC's economic development achievements, the 3,025-mile ADHS, is now more than three-fourths complete or under construction. According to the ARC, "Hundreds of thousands of new jobs have been created in counties with access to the new highways” (ARC 2003). By 1990, Appalachia's poverty rate had been cut in half, and

\footnotetext{
${ }^{2}$ Appalachian Regional Commission at http://www.arc.gov.
} 
per capita income has risen from 78 percent of the national average in 1965 to 84 percent currently.

The topography and low population density of Appalachia often prohibit standard infrastructure development or make it prohibitively expensive. Unfinished portions of the ADHS pass through some of the nation's most challenging mountainous terrain and could cost as much as \$20 million per mile, compared with the regional average of \$11 million per mile. The Transportation Equity Act for the 21st Century (TEA-21) authorized \$450 million annually, from FY 1999 through FY 2003, from the Highway Trust Fund for the ADHS. However, federal funding for ARC's regional development programs has been reduced for the 2004 fiscal year.

Figure 1 provides some information on the economic status of Appalachian counties. Most counties designated as distressed are concentrated in Central and Southern Appalachia, in places characterized by weak economic fundamentals like Alabama, Kentucky, Mississippi, southern Ohio, Tennessee, and West Virginia.

Regional development policies are usually geared to attract more industry and commerce, and consequently to spur economic activity. Research findings that more clearly demonstrate the impact of costly highway projects on output or productivity in economically disparate Appalachian counties can assist in framing informed regional development policy. The results from this dissertation indicate that distressed, nonmetropolitan counties gain most from major highway investments. Since the ADHS' primary purpose was to alleviate the isolation and poverty of these counties, it seems that the costly highway project has successfully contributed to the region's economic growth. More detailed accounts of the results are provided in Section 1.3 below. 


\section{Figure 1: Map of Appalachia Depicting County Economic Levels}

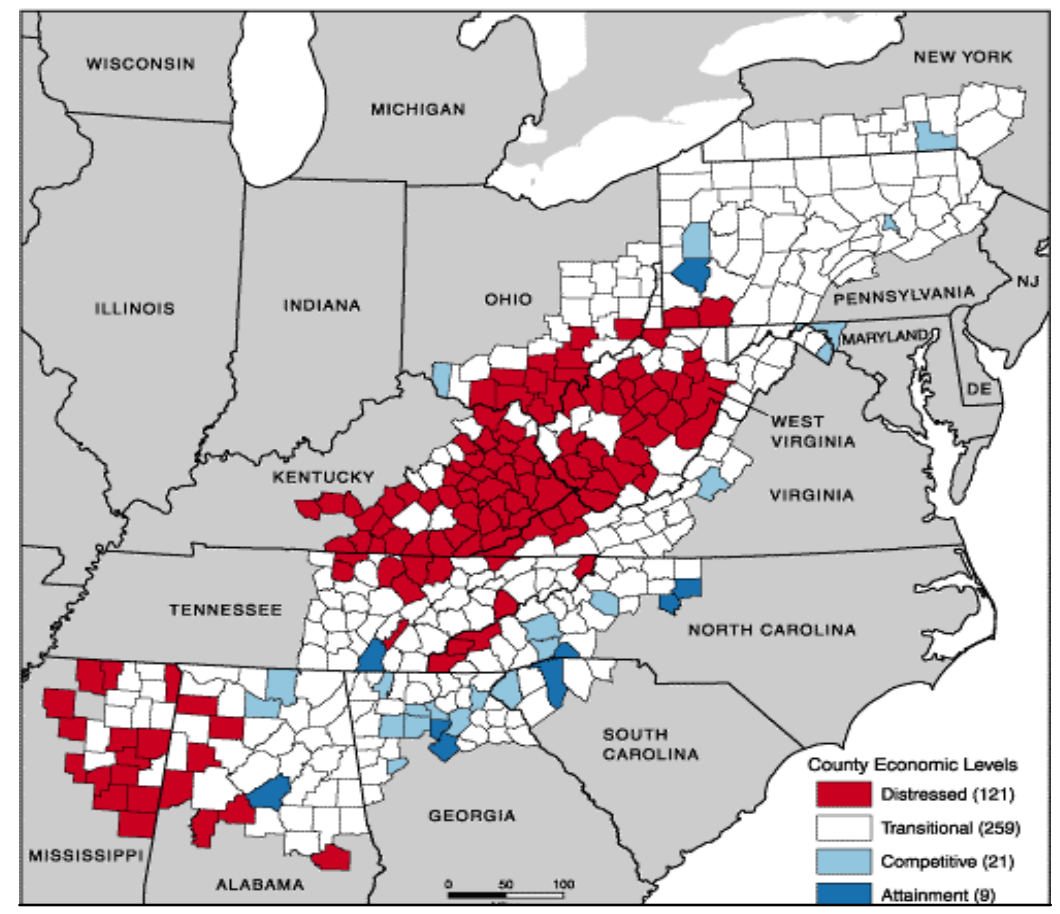

Source: Appalachian Regional Commission

\subsection{Dissertation Outline}

This section describes the layout of my dissertation, which comprises three essays on the impact of highway infrastructure on the economic performance of Appalachian counties. The remainder of this dissertation is structured as follows: Chapters 2, 3, and 4 present the three essays. Chapter 5 provides a brief summary and conclusion as well as future research ideas. Below is a brief description of the results from Chapters 2, 3 and 4.

In Chapter 2, I develop an empirical model to determine and measure the distance decay $^{3}$ in the impact of the Appalachian Development Highway System (ADHS) on Appalachian employment. The issue is particularly compelling since the ADHS was

\footnotetext{
${ }^{3}$ Distance decay refers to the effect of road access (infrastructure) on employment growth diminishing with distance.
} 
primarily constructed to help stimulate this isolated, relatively economically backward region. Therefore, a spatial analysis of the ADHS' economic impact will provide useful insight relevant not only for the region under study, but also regarding the costeffectiveness and benefits of other expensive public highway projects with similar objectives. Spatial models give adequate consideration to interactions of actors in space and spatial interdependence. They, therefore, yield more conclusive and complete evidence of the effectiveness of expensive public projects, such as highways, on the regional economy.

Using a standard OLS model, I find that the effect of highway access diminishes with distance and is not significant beyond six miles. Intuitively, this finding makes sense because in rugged, mountainous Appalachia, six miles is considerable distance. Applying a spatial autoregressive model, however, I no longer find any evidence of distance decay. The distance decay effect is now captured by the spatial spillover parameter, which measures the diffusion/transmission of employment growth through space, i.e., where one county's employment growth directly affects its neighboring counties. Thus, my results confirm the presence of a spatial process underlying regional economic performance.

While Chapter 2 addresses the impact of highway access on employment in Appalachia, in Chapter 3, I focus on the extent of spatial externalities, or, spatial spillovers, of highway investment on output or productive activity in the presence of spatial autocorrelation. Accounting for spatial interdependence in analyzing the attributes of transportation services is necessary to avoid biased results and to assess the benefits of long-term and costly public highway investments. As an application of spatial estimation methods, this chapter also examines the direction of causality between highway 
investment and output. Although some causality studies have focused on public capital and growth, none looked at causality between highways and output in the presence of spatial autocorrelation.

Chapter 3 presents a comparative analysis of the performance of standard OLS vs. spatial econometric models in capturing the effects of highway capital on regional output. I find that spatial models do indeed perform better and get rid of the omitted variable bias of the OLS coefficient estimates. Test results suggest that the spatial autoregressive model best captures the underlying spatial process present in the data. The spatial regression results also indicate that, for Appalachian counties, gross output is negatively influenced by highway capital stock in neighboring counties, although the effect is small. This result confirms that neighbor's highway investment tends to draw employment and productive activity away from a county, i.e., a county will experience a decrease in its production levels given an increase in neighboring county’s highway capital stock.

Highway capital has generally been found to have only a limited effect on economic growth. The impact may further vary depending on the economic condition of a county at the time of highway construction. The response of declining regions to a stimulus such as a new highway may be different from the response of prosperous regions. Likewise, a highly developed urban center may respond differently than a less developed rural area. For policy purposes, Chapter 4 investigates whether highway accessibility fosters faster or higher development in some counties compared with others.

I apply spatial econometric methodology to evaluate the impact of highways on economically disparate counties. ${ }^{4}$ Moran's I tests indicate that for both 'distressed' and

\footnotetext{
${ }^{4}$ Appalachian counties are divided into four categories by the Appalachian Regional Commission (ARC) according to their economic status: 'distressed,' 'transitional,' 'competitive,' and 'attainment'.
} 
'transitional' counties, positive spatial spillovers are clearly evident. For the 'competitive' category (which also includes the 9 'attainment' counties), however, the spatial spillover parameter is not significantly different from zero. In 'distressed' counties, labor and public capital are the major determinants for increases in output or productive activity. Highway capital investments in neighboring counties do not have much of an influence. Labor, public capital and own highway capital are the strongest positive influences on output in the 'transitional' counties. Neighbor's highway capital has a negative backwash effect on own county output. 


\section{Chapter 2}

Distance Decay in the Impact of Highway Access and Spatial Spillovers of Employment Growth in Appalachia 


\title{
Distance Decay in the Impact of Highway Access and Spatial Spillovers of Employment Growth in Appalachia
}

\author{
Samia Islam \\ Department of Economics \\ West Virginia University \\ Morgantown, WV 26506 \\ Email: saislam@mail.wvu.edu \\ Phone: (304) 2932166
}

\begin{abstract}
This paper examines the distance decay in employment growth and the spatial spillovers of highway investment in the 411-county Appalachian Region. The impact of transportation infrastructure on regional employment can be reflected through changes in the accessibility of the region affected. Lack of connectivity implies lack of choice, advancement and opportunity. Space is continuous and, therefore, the impact of infrastructure transcends the boundaries of regions. A certain region may benefit from the positive externalities associated with a public works project, even though the facilities are located in another region. The extent of these spillovers can be determined by using a measure of proximity to highway infrastructure in a model of employment.
\end{abstract}

JEL classification: R120, R490, C210

Keywords: Spatial Spillovers, Distance Decay, Highways 


\subsection{Introduction}

One of the key factors in regional development is employment or job growth. If a region can attract people with new jobs, the new migrants to the region increase demand for goods and services. Consequently, as new job opportunities are created, more people can find employment. If a region is isolated from its neighbors, this process is stifled. Roads and highways play a significant role in enhancing regional employment potential by increasing regional accessibility.

The aim of this paper is to determine and measure the distance decay ${ }^{5}$ in the impact of the Appalachian Development Highway System (ADHS) on Appalachian employment. The issue is particularly compelling since the ADHS was primarily constructed to help stimulate this isolated, relatively economically backward region. Therefore, a spatial analysis of the ADHS' economic impact will provide useful insight relevant not only for the region under study, but also regarding the cost-effectiveness and benefits of other expensive public highway projects with similar objectives in the future.

In order to determine whether the region's employment growth pattern has a spatial pattern, first I run an OLS model and conduct standard tests that indicate presence of spatial effects. Based on these findings, I use appropriate spatial econometric methods to estimate the magnitude of this spatial interdependence with a county-level model of Appalachian employment growth. Further diagnostic tests are done to check for the robustness of the results. Finally, I map the residuals of employment growth to see if the spatial patterns correspond to the socio-economic trends in the region during the past decade.

\footnotetext{
${ }^{5}$ Distance decay refers to the effect of road access (infrastructure) on employment growth diminishing with distance.
} 
Transportation comprises about 15-20 percent of the total public expenditure at the state or national level in the United States (Banister and Berechman, 2000). The share of transportation-related final demand in GDP has fluctuated slightly between 10.5 percent and 11.0 percent from 1975 through 2000. Only housing, health care, and food accounted for greater shares of GDP in 2000 (Figure 2.1).

Public capital is the primary source of funding for transportation infrastructure development. During the 1985 to 1999 period, highways comprised almost two-thirds (61 percent, on average) of total government transportation spending (Figure 2.2). In 2000, the accumulated public capital stock in highways and streets was valued at \$1.4 trillion (current dollars). From 1988 to 2000, the value (in chained 1996 dollars) of highway capital stock increased by 25 percent (TSAR 2001).

Market failures can occur in the provision of some facilities where, if left to the private sector, they would either be provided sub-optimally or not at all. Because these facilities contribute to positive social welfare, the public sector has to step in to provide the services. The transportation sector is especially prone to such market failures, since it is characterized by externalities (both positive and negative). Government involvement can internalize these externalities. Transmission of positive spatial externalities of public capital investment in highways may trigger regional growth. This paper investigates the spatial effects that public access to transportation has on regional employment growth.

The paper proceeds by laying out the general objective of the paper as well as the motivation behind it in Section 2.2. A literature review is presented in Section 2.3, which in turn, is divided into two sub-sections: one for the literature that is available on highway investment; and the other on spatial spillover analysis. This is appropriate not only due to 
the number of studies that have been done in these areas but also because very few of them have looked at the two issues simultaneously. Section 2.4 introduces the region and its salient characteristics. A detailed description of the methodology and data sources are presented in section 2.5, followed by the results presented in Section 2.6, and the concluding comments in Section 2.7. All tables and figures are included at the end of the chapter.

\subsection{General Objective}

This paper examines distance decay in highway access and spatial spillovers of highway investment in Appalachia. Before we proceed, it is necessary to clearly define spatial spillovers, especially since the literature does not seem to agree on one unique definition. For the purposes of this paper, we can think of spatial spillovers as economic benefits that trickle down from a source to factors within its immediate vicinity. Though the concept of vicinity has the idea of access (or, distance) embedded in it, the roles of access and spatial spillovers are generally overlooked (Rephann 1993, Kelejian and Robinson 1997).

Benefits of a highway will affect those living in its immediate vicinity. Commuters from other areas who did not have convenient access to that region prior to the road's construction will also benefit from it. Improved access has three significant impacts: (1) population growth (increase in labor supply), (2) income growth (increase in labor demand), and (3) reduced travel times (decrease in travel costs). These impacts may expand the labor inflow and outflow of relevant regions. 
Highways increase connectivity between regions, increasing accessibility to both labor and capital, which eventually translates into regional economic growth. Growth resulting from other economic stimuli, on the other hand, can also increase regional demand for transportation and access. An economic stimulus in one place (e.g., a county) will influence the economic performance of adjacent places, given that space is continuous. Space, however, is not homogenous. Places adjacent to each other can be characteristically different, in terms of their economic performance (distressed vs. growing regions) or in terms of concentration of economic activity (core vs. periphery).

The model I have developed uses employment growth as the dependent variable. My intention is to determine how the region's highway capital investment affects employment. The highway capital outlay variable reflects the total federal, state and local outlays on highways in 1990. The right hand side variables include amenities and other place characteristics (cost of living, net corporate business tax) that affect a county's appeal as a location choice. Amenities and place characteristics figure prominently in both firm and household location decisions. If the region is not appealing, no amount of highway investment will attract jobs and people to the region.

Beginning of period (1990) employment level, education rate, and poverty status of these counties are other logical choices for independent variables. These influence the performance of a region during the decade. A dummy variable accounts for the degree of urban influence, with a 1-0 value indicating metro or non-metro counties as categorized in the Census 1990 data.

It is interesting to see whether distance decay occurs, i.e., the effect of highway infrastructure on employment growth diminishes with increasing distance. It stands to 
reason that the closer a population center is to a highway, the greater the impact on its employment. Therefore, a highway’s impact should be strongest in areas adjacent to it.

\subsection{Literature}

\subsubsection{Highway Investment}

Many studies on public capital accumulation and its impact on economic growth have looked at public capital outlays in the aggregate (Aschauer 1989a). Aschauer's initial paper was followed by his own work (1989b, 1993) and that of Munnell (1990a), Holtz-Eakin (1988, 1992, 1995), Kocherlakota and Ke-Mu Yi (1992), Fernald (1993, 1999), and de Frutos and Pereira (1993). These papers that found substantial returns to public infrastructure have generated criticisms from other researchers (Aaron 1990, Schultze 1990, Hulten and Schwab 1991a, Rubin 1991, Jorgenson 1991 and Tatom 1991a, 1991b, 1993). Vickerman (2000) finds that these studies are not sufficiently robust to reflect the overall impact of highway investment on regional economies.

Baum and Behnke (1997) have suggested that half of German economic growth over the period between 1950 and 1990 is attributable to transport, half of which is road transport alone. In the United States, the interstate highway system's completion gave rise to studies that looked at transportation infrastructure explicitly during the 1970s. Rephann (1993) provides a comprehensive summary of pre-1990 literature regarding highway effects on growth. According to his survey, studies looking at distance decay of highway effects have found that interchange development is associated with several geographic, economic, and traffic variables. These include (1) topography, (2) distance

from cities, (3) distance from adjacent interchanges, (4) population density, (5) volume of 
traffic, and (6) existing development near highways (Mason 1973; Corsi 1974; Epps and Stafford 1974; Twark et al. 1980; Moon 1988).

The effects of highways on rural or nonmetropolitan areas atrophy with increasing distance and disappear beyond a distance of 25 miles (Humphrey and Sell 1975; Briggs 1980; Lichter and Fuguitt 1980). Wheat (1969) finds that growth is generally higher near the interstate and tapers off with increasing distance in a pattern that can be described as "a bell-shaped curve peaking at zero miles and having a standard deviation of five miles."

Rephann and Isserman (1994) use a quasi-experimental matching method to determine the effect of new highways on regional growth. Using U.S. county data, they found that counties proximate to counties with a population exceeding 25,000 gained the most from new highways. Rural counties were affected only moderately. Counties adjacent to highway-impacted counties actually were negatively affected (due to transfer of resources to the impacted county). Moomaw, Mullen and Williams (1995) found a weak role of highways at the state level, accounting for spatial variation in the impact of public capital. Bruinsma, Rienstra and Rietveld (1997) found that the establishment of new firms occurs within a 7.5-mile radius of a new highway. Boarnet (1998) looked at county spillovers of employment, population and income. He interpreted negative spillover effects between neighboring counties as a competition effect between similarly urbanized counties.

Regional production function studies usually have found transportation infrastructure to be an important determinant of regional output (Mera 1975; Blum 1982; Nijkamp 1986; Deno 1988; Anderson et al. 1990, Lynde and Richmond 1993), though some have found the effect to be rather small, even after controlling for state effects 
(Garcia-Mila and McGuire 1992; Munnell 1990b). Holtz-Eakin and Schwartz (1995) looked at productivity spillovers from state highways, but found only limited empirical evidence of cross-state effects of highways on productivity and output.

Urbanized and dynamic areas tend to be disproportionately favored for new highways (Humphrey and Sell 1975; Briggs 1980; Lichter and Fuguitt 1980). Urban areas, however, have existing favorable conditions that make them more likely to grow faster than rural regions. Failure to control for these circumstances and to isolate the effects of the prior conditions from the highway effects can upwardly bias estimates of highway effects.

Highway socio-economic effects appear to be greater in more densely populated urbanized and metropolitan areas (Chernoff 1978; Isserman et al. 1989). Generally, highways have been found to have greater impact on less industrialized regions. Urbanization level and metro proximity are important determinants, and declining regions respond less than slow growing regions.

Rietveld and Boonstra (1995) find a nonlinear relationship between population density and highway infrastructure density in their study of 92 European regions. In densely populated regions, highway supply is smaller than expected based on a linear relationship. They explain that car use in urban areas is lower than in rural areas, because car ownership is lower and trip distances are shorter in cities, which tend to be more compact.

Chandra and Thompson (2000) examine the relationship between large infrastructure spending on highways and the level of economic activity and find that rural interstate highways affect the spatial allocation of economic activities and raise the level 
of activity in counties that they pass directly through at the expense of economic activities in adjacent counties.

New economic geography (Krugman 1991, Krugman and Venables 1995, Martin 1998, Venables and Gasoriek 1999, Puga 2002) literature emphasizes that the effects of public infrastructure depend critically on a region's industrial composition. The single equation approach that Aschauer (1989a) used does not differentiate between different sectors of the economy.

Although many studies mentioned above have evaluated the economic impact of public infrastructure across the U.S. states, few have specifically looked at highways. Studies that have examined highways have generally found their impact to be the strongest on metropolitan regions. Almost all findings support the theory that the effect tapers off with increasing distance. In rugged and mountainous Appalachia, we expect the effect of the ADHS highways to fade out at an even faster rate than in the rest of the United States.

\subsubsection{Spatial Spillovers}

Spatial analysis is attracting increasing attention from economists. The effect of public capital has been found to range from positive to negative and everything in between, including no role at all (Mikelbank and Jackson 2000). In recent years, regional economists have begun to assimilate spatial analysis methodologies more commonly applied by geographers. Space has taken on a new significance in regional analysis as more researchers have come to appreciate that places are not isolated entities, functioning independently of their surrounding locations. Most economic processes have a spatial component embedded in them where any activity in one place carries forth through space 
to affect its neighbor. Not accounting for this diffusion effect yields an incomplete analysis. Over the years, studies have used complex spatial methodologies to model the effects of public capital infrastructure on regional economic performance. Anselin (1988, 2001, 2003) has made major contributions to spatial econometric theory in recent years. This paper draws heavily on his work for research methodology, especially in specifying and quantifying spatial externalities.

Brueckner's (2003) spillover model provides a theoretical framework for strategic interactions that yield a reaction function as the equilibrium solution. Moomaw, Mullen and Williams (1996) used a state-specific, time invariant fixed effect in their model and revealed two distinct public capital roles in manufacturing efficiency determination while paying close attention to their spatial outcome. Holtz-Eakin (1994) considered positive spillovers more broadly and aggregated state data to multi-state regions, expecting, but not finding, higher public capital coefficients due to the capture of spillover effects.

Kelejian and Robinson (1997) looked at both productivity and infrastructure spillovers across states but did not find conclusive evidence of the latter. Williams and Mullen (1998) find significant positive cross-state spillovers of highways capital, with the effect strongest in the southern U.S. states. They conclude that higher highway investment in the southern states would provide the region with a competitive edge in manufacturing.

Martin (1998) and Puga (2001) suggest that if public policies attempt to affect economic geography through infrastructure, they may result in lower growth everywhere. 
This literature, however, focuses on industrial clustering and does not address what happens when new infrastructure connects geographically isolated places.

Based on the few studies that have looked into spatial spillovers of highways, there appears to be no consensus. Spillovers range from positive to negative. Some have found cross-state positive spillovers of highway capital. In most cases, after accounting for spillovers, the coefficient of public capital turns out to be higher. No studies have looked at spatial spillovers at the county level.

\subsection{Methodology and Data}

The analysis was carried out for cross-sectional units (i.e., counties) in the 13 Appalachian states. Since many studies have found that highway development most favorably affects areas with high population density (Humphrey and Sell 1975; Briggs 1980; Lichter and Fuguitt 1980; Chernoff 1978; Isserman et al. 1989), the analysis focuses on the population centers in each Appalachian county. I calculated the population centroids for all 411 counties in Appalachia, using 1990 Census population data. Using ARCView shape files for the counties and major roads in the region, I calculated the distance of each centroid from the nearest ADHS corridor or interstate highway.

As a necessary first step towards determining the distance decay in employment, the study considers population centroids that are within a 25-mile radius of any ADHS corridor or an interstate highway. We can think of this as the 'access area'. If my results reveal a significant coefficient up to a distance of 25 miles, the radius can be easily extended.

My method for deriving a distance matrix involved creating a set of dummy variables, one each for the county population centroids that are within 0-2 miles; within 4 
miles but beyond 2 miles; within 6 miles but beyond 4 miles; within 8 miles but beyond 6 miles; within 10 miles but beyond 8 miles; within 12 miles but beyond 10 miles; within 14 miles but beyond 12 miles; within 16 miles but beyond 14 miles; within 18 miles but beyond 16 miles; within 20 miles but beyond 18 miles; within 22 miles but beyond 20 miles; or, within 25 miles but beyond 22 miles of the nearest ADHS corridor or major interstate highway.

Model:

EMPGR $=\alpha+\beta_{1}($ LHWY $)+\beta_{2}($ LEMP90 $)+\beta_{3}($ EDURATE90 $)+\beta_{4}($ UR90 $)+$ $\beta_{5}($ POVERTY90 $)+\beta_{6}($ MT_NMTR90 $)+\beta_{7}($ BIZTAX $)+\beta_{8}($ LIVCOST $)+$ $D V 2+\ldots+D V 25+\varepsilon_{1}$

The dependent variable is EMPGR, which is the rate of employment growth between 1990 and 2000. Different data sources define employment in a variety of ways. This study uses wage and salary employment by place of work, published by the U.S. Bureau of Economic Analysis (BEA). This measure of employment is more comprehensive than either the Census Bureau's County Business Pattern data or the covered employment and wages (ES202) data published by the U.S. Bureau of Labor statistics (BLS). Table 2.1 describes each of the RHS variables.

Initially, it appeared that using population centroids instead of cities may not be methodologically sound. Depending on the land area of counties, the calculated centroids could have missed the actual areas with high population densities, i.e., the largest cities. However, an overlay of the centroids on a map of 1990 census designated places revealed that almost all of the centroids coincide with actual population concentrations, with the exception of about two dozen counties which were then re-assigned manually. 
Most of the demographic and socio-economic data, namely, poverty status, educational achievement, unemployment rates and urban influence codes were acquired from U.S. Bureau of the Census, U.S. Department of Labor and U.S. Department of Agriculture (USDA) sources.

Highway capital outlay data by state was obtained from the Federal Highway Administration (FHWA). This data was used to generate county estimates by apportioning state totals to counties using the population ratio, i.e., county population as a proportion of state population, as weights.

BIZTAX, a state's net effective corporate tax rate, is included to represent a states’ business environment. LIVCOST, a composite index of households' expenditures on housing, grocery, utilities, transportation, healthcare, and miscellaneous, measures a state's cost of living.

Business tax (BIZTAX) and cost of living (LIVCOST) data were obtained from MERIC and the University of California, San Diego (UCSD)'s Social Science Data Collection (SSDC) center. MERIC (Missouri Economic Research and Information Center, Missouri Department of Economic Development) derives the cost of living index for each state by averaging the ACCRA Cost of Living indices of participating cities and metropolitan areas in that state. ${ }^{6}$

Cost of living indices usually are not perfect and each agency uses a different method to estimate them. Comparison of the ACCRA estimate with data from UCSD did not reveal a significant difference. However, according to McMahon and Chang (1991),

\footnotetext{
6 The ACCRA Index measures relative price levels for consumer goods and services in participating areas. The average for all participating places, both metropolitan and nonmetropolitan, equals 100, and each participant's index is read as a
} 
housing prices are the most significant component of cost-of-living estimation. Therefore, median housing prices in lieu of the state-level cost of living estimates can also be used in the model. One advantage of median housing price data is its availability at the county level.

The study uses SAS, ARCView, MABLE/GEOCORR, and Spacestat to carry out the data analysis.

\subsection{Results}

The preliminary results (Table 2.2) match my expectations with respect to the highway effect: the farther away an Appalachian population center is from an ADHS corridor or an Interstate, the lower the road infrastructure's impact on the county's employment. The effect of highway access diminishes with distance and is not significant beyond six miles. An F-test for the joint significance of the insignificant distance dummy variables does not reject the null hypothesis that they all equal zero. Intuitively, this finding makes sense because in rugged, mountainous Appalachia, six miles is a considerable distance. In sum, we find that proximity to highways has a statistically significant effect on a region's employment, but is subject to distance decay.

It is, however, important to keep in mind that highways often run through river valleys, and certainly avoid the roughest terrain. This suggests that highways typically pass through areas where the terrain is also favorable for residential and business development. Thus, highway effects obtained from an empirical analysis that does not consider the geographic variation in the terrain proximate to the highways may also pick

percentage of the average for all places. The Index does not measure inflation (price change over time). Each quarterly report is a separate comparison of prices at a single point in time. 
up the effects of pre-existing favorable conditions for development. Given the preponderance of hilly terrain in the Appalachian sample, these two effects cannot be adequately distinguished. This issue could be addressed more completely with a broader, less homogenous sample (e.g., all U.S. counties)

Highway capital outlay, employment level in 1990, unemployment rate, poverty rate, educational attainment rate, and cost of living also have statistically significant coefficients, with expected signs. Among the statistically significant variables, highway capital outlay and education rate have positive signs, implying that an increase in either would induce an increase in regional employment growth. Unemployment rate and cost of living have negative signs meaning that a reduction in either would increase employment growth. Employment in 1990 has a negative sign as well, implying that the places that had high employment (larger counties) in the initial period would experience slower job growth, compared with less populous counties.

Moran's I test on the OLS model yields a highly significant positive value. This indicates the presence of spatial autocorrelation and the need for spatial analysis. By mapping the residuals (Figure 2.3) of employment growth from the OLS model we can attempt to determine whether the growth process follows a spatial pattern, i.e., if evidence of spatial clustering exists. The residuals of employment growth are measured as the number of standard deviations above $(+)$ or below $(-)$ the mean (or, the actual growth), with a negative value reflecting that the predicted values that exceed the actual values.

The OLS model over-predicts employment growth for most of northeastern Appalachia (some north-central counties of Pennsylvania and the lower tier of New York 
counties) and central Appalachia (some counties of Virginia and West Virginia), and some clustering occurs. It under-predicts employment growth in southeastern Appalachia. In states such as Alabama, the distribution is random indicating only a limited spatial autocorrelation effect.

Spatial autocorrelation (more generally, spatial dependence) exists when the dependent variable or error term at each location is correlated with observations on the dependent variable or values of the error term at other locations (Anselin 1988). The general case is formally:

$$
E\left[\varepsilon_{i} \varepsilon_{j}\right] \neq 0
$$

for neighboring locations $i$ and $j$. This specification is too general to allow for the estimation of potentially $\mathrm{N}$ times $(\mathrm{N}-1)$ interactions from $\mathrm{N}$ observations. Therefore the form of the spatial dependence is given structure by means of a spatial weights matrix (W), which reduces the number of parameters to one (Anselin 1988).

Two important alternative spatial models might be appropriate depending on the consequences of ignoring spatial dependence. The spatial lag model reflects misspecification similar to omitting a significant explanatory variable in the regression model. The spatial error model pertains to errors that are not homoskedastic and uncorrelated, as assumed. In the latter case, OLS is still unbiased, but no longer efficient. In the first case, however, OLS is biased and all inferences based on the standard regression model will be incorrect.

Model choice initially depends on the underlying theory. In our case, theory suggests the spatial lag model because the spatial error model (SEM) treats the spatial process as a nuisance. SEM is applicable in studies such as those focusing on agricultural 
land prices where the localization of land becomes crucial because land is not a mobile asset. In regional or local markets if the main difference among producers is given by the distance between the market and the plot of land, then among land plots with the same characteristics, the more valuable land is the one located in the better position with respect to the market. In a classic example of spatial error dependence, Benirschka and Binkley (1994) found that the less favorably located plots (with respect to the location of the market) were more affected by land price changes than the ones located near the market. In this essay, however, spatial autocorrelation can not be looked at as a nuisance since highways have a direct impact on people's mobility and accessibility.

To make sure that the model is compatible with the theory, Spacestat includes four tests. The first is an extension of the Moran's I, which measures spatial autocorrelation in regression residuals. Although widely used, this test is somewhat unreliable. $^{7}$

The Lagrange Multiplier test is an asymptotic test that follows a $\chi^{2}$ distribution with one degree of freedom and tests for error dependence. ${ }^{8}$ The third test is the KelejianRobinson statistic, ${ }^{9}$ which is a large sample test and does not have much power for small datasets. Unlike the first two tests, it does not require normality of errors, or linearity of the regression model. It may not be the proper indicator in our case due to the sample size. The final test is a Lagrange Multiplier diagnostic for a spatial lag. This test is only valid under assumptions of normality (Anselin 1988) and is asymptotic in nature. As is its

\footnotetext{
${ }^{7}$ As found by Anselin and Rey (1991), this test picks up a range of misspecification errors, such as nonnormality and heteroskedasticity, as well as spatial lag dependence. Moreover, it does not test for presence of error dependence.

${ }^{8}$ Burridge (1980).

${ }^{9}$ Kelejian and Robinson (1992).
} 
counterpart for spatial errors, the LM lag test is distributed as a $\chi^{2}$ variate with one degree of freedom.

According to Anselin and Rey (1991), the joint use of the LM-err and LM-lag statistics provides the best guidance with respect to the alternative model, as long as the assumption of normality is satisfied. The authors also affirm that when both tests have high values (indicating spatial dependence), the one with the highest value (lowest probability) will tend to indicate the correct alternative. The probabilities of the LM-error and LM-Lag tests from my model are 92.59 and 90.57 respectively. The lower probability for the LM-lag test confirms the appropriateness of the spatial lag model. ${ }^{10}$

In the modified model, I apply Anselin's (1988) methodology to construct a spatial lag model with employment growth as the dependent variable:

$$
\mathbf{y}=\rho \mathbf{W y}+\mathbf{X} \beta+\mathbf{u}
$$

The reduced form of this equation would be:

$$
\begin{aligned}
& y=(1-\rho W)^{-1} X \beta+(1-\rho W)^{-1} u \\
& \text { and, } \quad E[y \mid X]=(1-\rho W)^{-1} X \beta
\end{aligned}
$$

Moran's I test on the OLS model has already established the presence of a spatial pattern in the growth process. To determine the extent of spatial spillovers, I used geographic contiguity as the weights matrix (W) to assign structure to the spatial interdependence that is likely present across the counties in the region. In this model, when only direct neighbors interact, the local spatial multiplier $W X$ or $(1-\rho W)^{-1} X$ measures the spatial spillovers. In other words, the parameter, $\rho$, reflects the level of

\footnotetext{
${ }^{10}$ A more detailed discussion of the model selection process is presented in the next chapter.
} 
diffusion or spatial spillovers. Results are presented below in Table 2.3 (with z-stats in parentheses), for all 411 Appalachian counties.

The spatially weighted dependent variable (W_EMPGR) designed to capture the spatial effect is highly significant. The magnitude of the coefficient states that when employment growth went up by 1 percent, about a tenth of that could be attributed to the spatial effect. All other signs are as expected. The other significant variables include highway capital outlay, lagged employment, education rate, unemployment rate, poverty rate, and cost of living.

A likelihood ratio test is used to check for the reliability of the weights matrix (W) in the spatial lag model. ${ }^{11}$ A high likelihood ratio of 69.17 confirms that the $\mathrm{W}$ matrix in our model is appropriate. Further, an LM test reports a value of 0.001 with a probability of 0.97 suggesting that spatial dependence has been eliminated.

A map of the spatial lag model residuals (Figure 2.4) shows that the spatial patterns of employment growth are no longer as evident as in the OLS case. Clusters give way to randomness across the region, with the exception of Pennsylvania where some clustering still persists, leading us to surmise that the decline of the 'rust belt' is affecting the results. All across Appalachia, growth seems to be under-predicted in counties surrounding large metro areas.

\subsection{Conclusion}

This paper takes two topics that have been widely discussed in the literature and merges them to examine the effectiveness of a large-scale, costly regional highway project. Omitting spatial effects while examining the effect of highways (that directly

\footnotetext{
${ }^{11}$ The $\mathrm{W}$ matrix used here is a row-standardized, first-order contiguity matrix.
} 
affect labor mobility) on employment will only reveal a partial truth. Intuitively, the methodology used in this study makes greater sense because it provides a more comprehensive analysis of the two interminably linked issues of space and access.

Although this paper focused on Appalachia, the results have broader relevance. Lack of evidence of distance decay, once the proper spatial model is applied, can contribute in developing consistent policy in other mountainous regions. It also helps to ensure greater efficiency of highway capital, better evaluation of user benefits, and an acknowledgment of the need to target economically disparate places to achieve sustainable regional development.

Earlier studies that did not account for the effect of spatial autocorrelation likely presented results that were biased. In my paper, I find that spatial patterns are evident in Appalachian employment growth. OLS results are, therefore, biased. Further tests reveal that the Spatial Lag Model eliminates spatial autocorrelation.

The new economic geography literature disputes findings of aggregate studies that do not account for industrial clustering (Puga 2002, Martin 1999). However, this paper focuses on employment growth in a region hindered by its isolation and for the most part, not characterized by industrial or technology clustering. The distribution of clusters throughout Appalachia is highly uneven. Just over half of the technology clusters in the region are located on the periphery and are anchored in core metropolitan centers outside the region such as Cincinnati, Atlanta, and Washington, DC (ARC 2003). Therefore, the results presented here do not lose much in the absence of sectoral breakdown.

In a mountainous region, such as Appalachia, highways are most often constructed on terrain that is favorable to economic and residential development. Thus, 
highway effects obtained from the empirical analysis may also be picking up effects such pre-existing favorable conditions. It is impossible to distinguish between these two effects given the data limitations for Appalachian counties, but with a broader sample (e.g., using all U.S. counties) this issue can be addressed more completely.

Given that Vickerman et al. (1999) have found access to networks to be a key issue in highway provision, other possible future extensions could examine whether highway networks have a larger growth impact whenever a significant network size is achieved (similar to telecommunication networks). This would imply that positive growth effects might be subject to reaching a critical mass in a given region's transportation infrastructure. It is, therefore, necessary to consider the possibility of nonlinearities. Also, the potential interaction between new road investment and changes in employment could be captured by extending the model with two additional equations that allow for simultaneity between these two variables. 


\section{$\underline{\text { Tables and Figures }}$}

\section{Table 2.1: List of Explanatory Variables}

\begin{tabular}{|c|c|}
\hline LHWY & Log of highway capital outlay by county in 1990 \\
\hline LEMP90 & Log Employment by county in 1990 \\
\hline EDURATE90 & Percent of people, 25 and older, with high school degree or higher in 1990 \\
\hline UR90 & Unemployment Rate in 1990 \\
\hline POVERTY90 & Number of people below poverty level in 1990 \\
\hline MT_NMTR90 & Dummy to reflect urban influence \\
\hline BIZTAX & Net effective corporate business tax (\%) \\
\hline LIVCOST & $\begin{array}{l}\text { A cost of living composite index, that includes expenditure on housing, grocery, } \\
\text { healthcare, transportation, utilities \& misc. }\end{array}$ \\
\hline DV2 & $\begin{array}{l}\text { Dummy variable for population centroids within a distance of } 2 \text { miles of nearest } \\
\text { ADHS or Interstate }\end{array}$ \\
\hline DV4 & $\begin{array}{l}\text { Dummy variable for population centroids beyond a distance of } 2 \text { miles but within } \\
\text { a distance of } 4 \text { miles of nearest ADHS or Interstate }\end{array}$ \\
\hline DV6 & $\begin{array}{l}\text { Dummy variable for population centroids beyond a distance of } 4 \text { miles but within } \\
\text { a distance of } 6 \text { miles of nearest ADHS or Interstate }\end{array}$ \\
\hline DV8 & $\begin{array}{l}\text { Dummy variable for population centroids beyond a distance of } 6 \text { miles but within } \\
\text { a distance of } 8 \text { miles of nearest ADHS or Interstate }\end{array}$ \\
\hline DV10 & $\begin{array}{l}\text { Dummy variable for population centroids beyond a distance of } 8 \text { miles but within } \\
\text { a distance of } 10 \text { miles of nearest ADHS or Interstate }\end{array}$ \\
\hline DV12 & $\begin{array}{l}\text { Dummy variable for population centroids beyond a distance of } 10 \text { miles but within } \\
\text { a distance of } 12 \text { miles of nearest ADHS or Interstate }\end{array}$ \\
\hline DV14 & $\begin{array}{l}\text { Dummy variable for population centroids beyond a distance of } 12 \text { miles but within } \\
\text { a distance of } 14 \text { miles of nearest ADHS or Interstate }\end{array}$ \\
\hline DV16 & $\begin{array}{l}\text { Dummy variable for population centroids beyond a distance of } 14 \text { miles but within } \\
\text { a distance of } 16 \text { miles of nearest ADHS or Interstate }\end{array}$ \\
\hline DV18 & $\begin{array}{l}\text { Dummy variable for population centroids beyond a distance of } 16 \text { miles but within } \\
\text { a distance of } 18 \text { miles of nearest ADHS or Interstate }\end{array}$ \\
\hline DV20 & $\begin{array}{l}\text { Dummy variable for population centroids beyond a distance of } 18 \text { miles but within } \\
\text { a distance of } 20 \text { miles of nearest ADHS or Interstate }\end{array}$ \\
\hline DV22 & $\begin{array}{l}\text { Dummy variable for population centroids beyond a distance of } 20 \text { miles but within } \\
\text { a distance of } 22 \text { miles of nearest ADHS or Interstate }\end{array}$ \\
\hline DV25 & $\begin{array}{l}\text { Dummy variable for population centroids beyond a distance of } 22 \text { miles but within } \\
\text { a distance of } 25 \text { miles of nearest ADHS or Interstate }\end{array}$ \\
\hline
\end{tabular}


Table 2.2: OLS Regression Results

\begin{tabular}{|c|c|}
\hline Employment Growth1990-2000 & Coefficient \\
\hline Intercept & $\begin{array}{l}\text { 78.60168*** } \\
(3.57)\end{array}$ \\
\hline LHWY & $\begin{array}{l}30.18693 * * * \\
(6.16)\end{array}$ \\
\hline LEMP90 & $\begin{array}{l}-26.89276^{* * * *} \\
(-7.06)\end{array}$ \\
\hline EDURATE90 & $\begin{array}{l}0.44868 * * * \\
(2.74)\end{array}$ \\
\hline UR90 & $\begin{array}{l}-1.66571^{* * *} \\
(-4.14)\end{array}$ \\
\hline MT_NMTR90 & $\begin{array}{l}0.98424 \\
(0.32)\end{array}$ \\
\hline POVERTY90 & $\begin{array}{l}-0.00015580 \\
(-1.13)\end{array}$ \\
\hline BIZTAX & $\begin{array}{l}0.51565 \\
(0.73)\end{array}$ \\
\hline LIVCOST & $\begin{array}{l}-1.21973 * * * \\
(-3.58)\end{array}$ \\
\hline DV2 & $\begin{array}{l}5.4672 * * \\
(2.03)\end{array}$ \\
\hline DV4 & $\begin{array}{l}4.95278 * * \\
(1.98)\end{array}$ \\
\hline DV6 & $\begin{array}{l}4.83919 * \\
(1.73)\end{array}$ \\
\hline DV8 & $\begin{array}{l}-1.69246 \\
(-1.00)\end{array}$ \\
\hline DV10 & $\begin{array}{l}2.21168 \\
(1.59)\end{array}$ \\
\hline DV12 & $\begin{array}{l}0.272237 \\
(0.25)\end{array}$ \\
\hline DV14 & $\begin{array}{l}0.481753 \\
(0.55)\end{array}$ \\
\hline DV16 & $\begin{array}{l}0.452349 \\
(0.54)\end{array}$ \\
\hline DV18 & $\begin{array}{l}-1.07253 \\
(-1.32)\end{array}$ \\
\hline DV20 & $\begin{array}{l}0.845611 \\
(1.17)\end{array}$ \\
\hline DV22 & $\begin{array}{l}0.0508392 \\
(0.08)\end{array}$ \\
\hline DV25 & $\begin{array}{l}-0.193125 \\
(-0.33)\end{array}$ \\
\hline $\mathrm{R}^{2}$ & 0.1665 \\
\hline
\end{tabular}


Table 2.3: Spatial Lag Model - Maximum Likelihood Estimation

\begin{tabular}{|c|c|}
\hline Employment Growth 1990-2000 & Coefficient \\
\hline W_EMPGR & $\begin{array}{l}0.0886128^{* * *} \\
(9.034731)\end{array}$ \\
\hline LHWY & $\begin{array}{l}27.6425 * * * \\
(6.293968)\end{array}$ \\
\hline LEMP90 & $\begin{array}{l}-22.4315 * * * \\
(-6.560062)\end{array}$ \\
\hline EDURATE90 & $\begin{array}{l}0.401141 * * * \\
(2.741264)\end{array}$ \\
\hline POVERTY90 & $\begin{array}{l}-0.0002892^{* *} \\
(-2.50035)\end{array}$ \\
\hline UR90 & $\begin{array}{l}-0.8592 * * * \\
(-2.622983)\end{array}$ \\
\hline MT_NMTR90 & $\begin{array}{l}1.56346 \\
(0.567621)\end{array}$ \\
\hline BIZTAX & $\begin{array}{l}0.148986 \\
(0.247373)\end{array}$ \\
\hline LIVCOST & $\begin{array}{l}-0.457393^{* *} \\
(-2.111506)\end{array}$ \\
\hline DV2 & $\begin{array}{l}2.56832 \\
(0.811271)\end{array}$ \\
\hline DV4 & $\begin{array}{l}0.00788331 \\
(0.003843)\end{array}$ \\
\hline DV6 & $\begin{array}{l}0.193229 \\
(0.104141)\end{array}$ \\
\hline DV8 & $\begin{array}{l}-0.579406 \\
(-0.367875)\end{array}$ \\
\hline DV10 & $\begin{array}{l}1.18171 \\
(0.908859)\end{array}$ \\
\hline DV12 & $\begin{array}{l}0.667457 \\
(0.652242)\end{array}$ \\
\hline DV14 & $\begin{array}{l}0.0125575 \\
(0.015260)\end{array}$ \\
\hline DV16 & $\begin{array}{l}0.603219 \\
(0.776664)\end{array}$ \\
\hline DV18 & $\begin{array}{l}-1.25949 \\
(-0.662037)\end{array}$ \\
\hline DV20 & $\begin{array}{l}0.685804 \\
(1.020316)\end{array}$ \\
\hline DV22 & $\begin{array}{l}0.329648 \\
(0.523502)\end{array}$ \\
\hline DV25 & $\begin{array}{l}-0.595381 \\
(-1.077792)\end{array}$ \\
\hline $\mathrm{R}^{2}$ & $\begin{array}{l}(-1.07 / 192) \\
0.2327\end{array}$ \\
\hline
\end{tabular}


Figure 2.1: Share of Sector-wise Final Demand in GDP

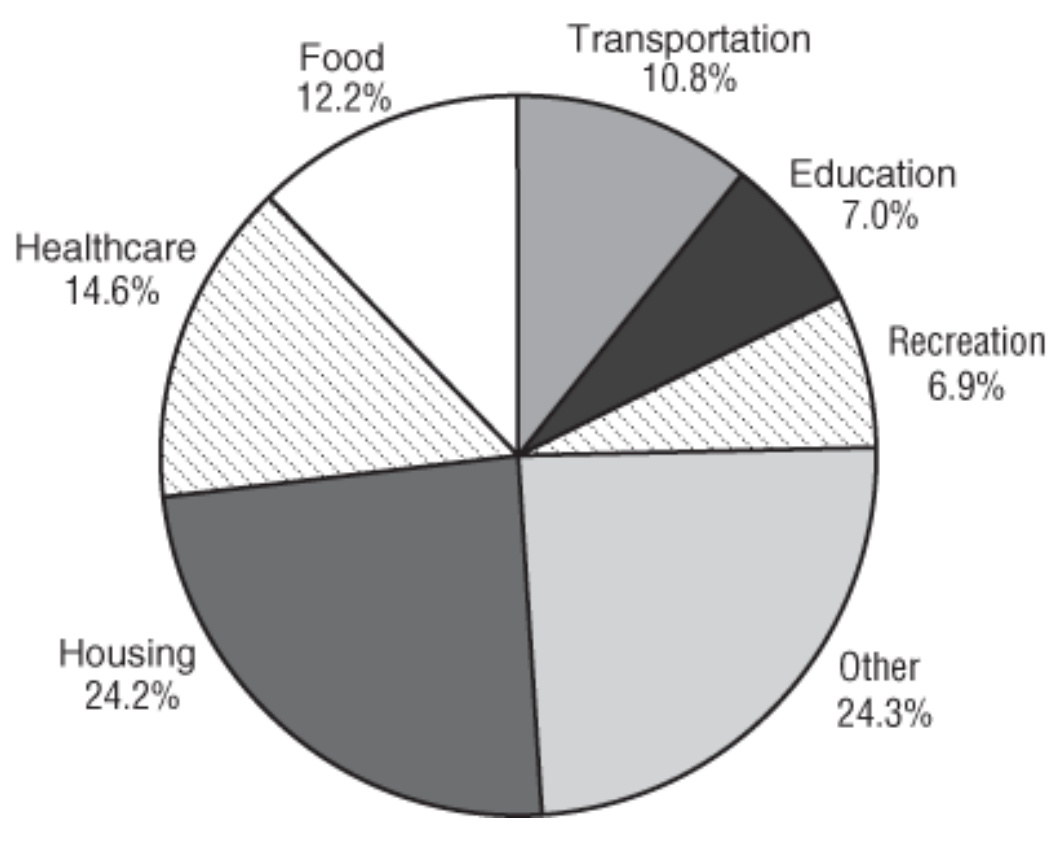

SOURCE: U.S. Department of Transportation, Bureau of Transportation Statistics, calculated from data in U.S. Department of Commerce, Bureau of Economic Analysis, Survey of Current Business, October 2001. 
Figure 2.2: Total Government Spending on Transportation, 1985-1999

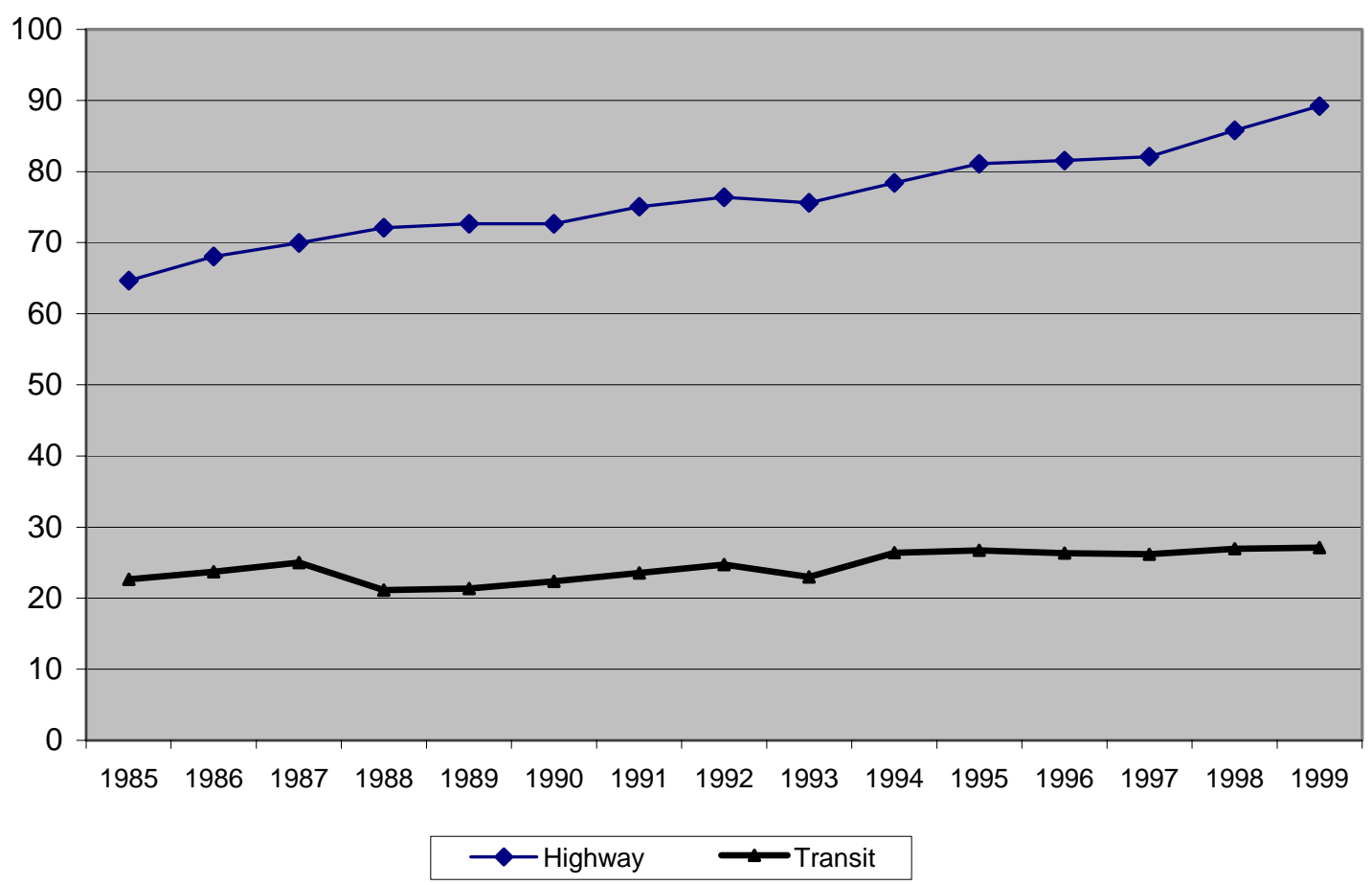

Source: Bureau of Transportation Statistics 
Figure 2.3: Mapping the OLS Residuals of Employment Growth

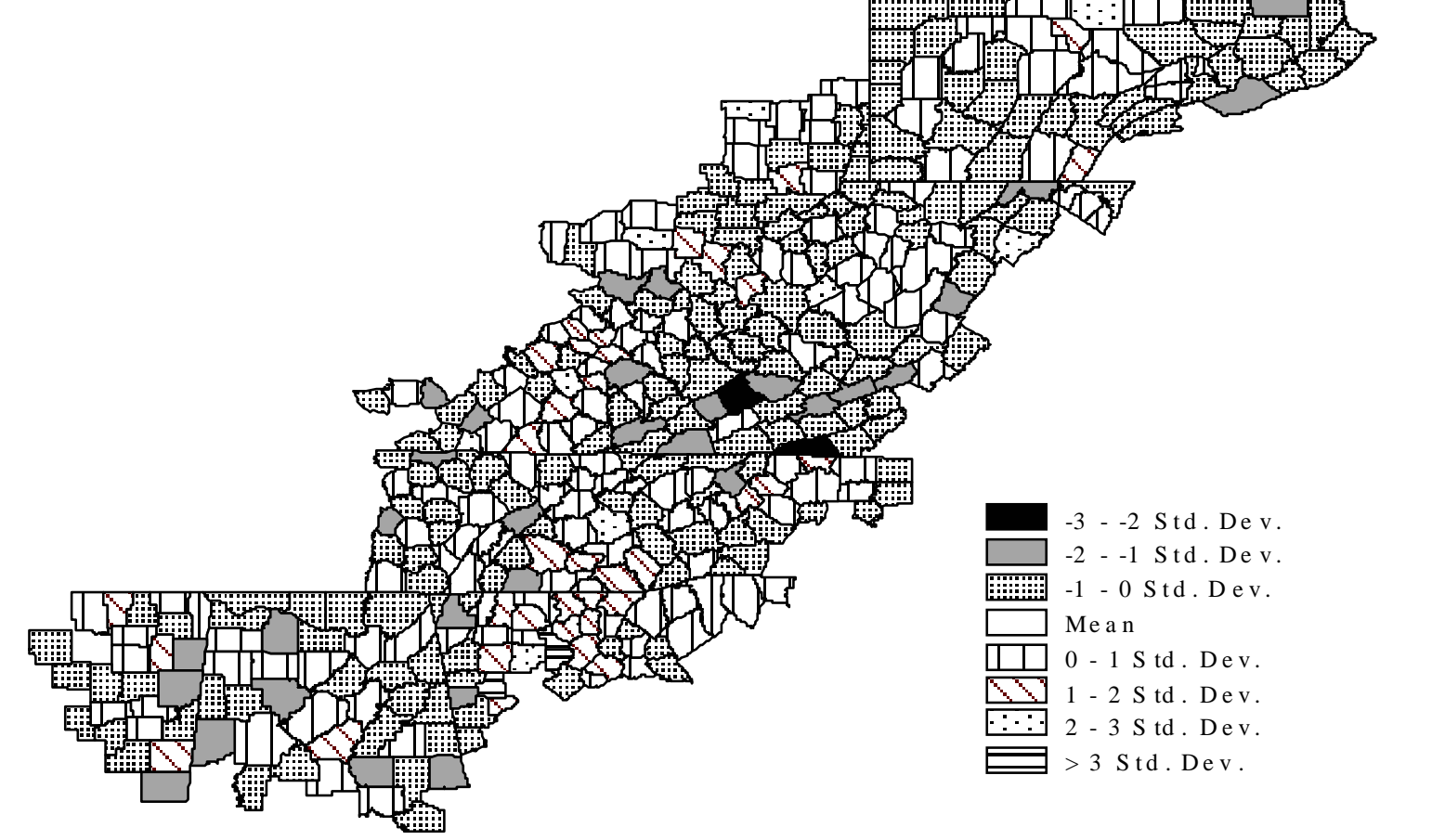


Figure 2.4: Mapping the Residuals of Employment Growth from the Spatial Lag Model

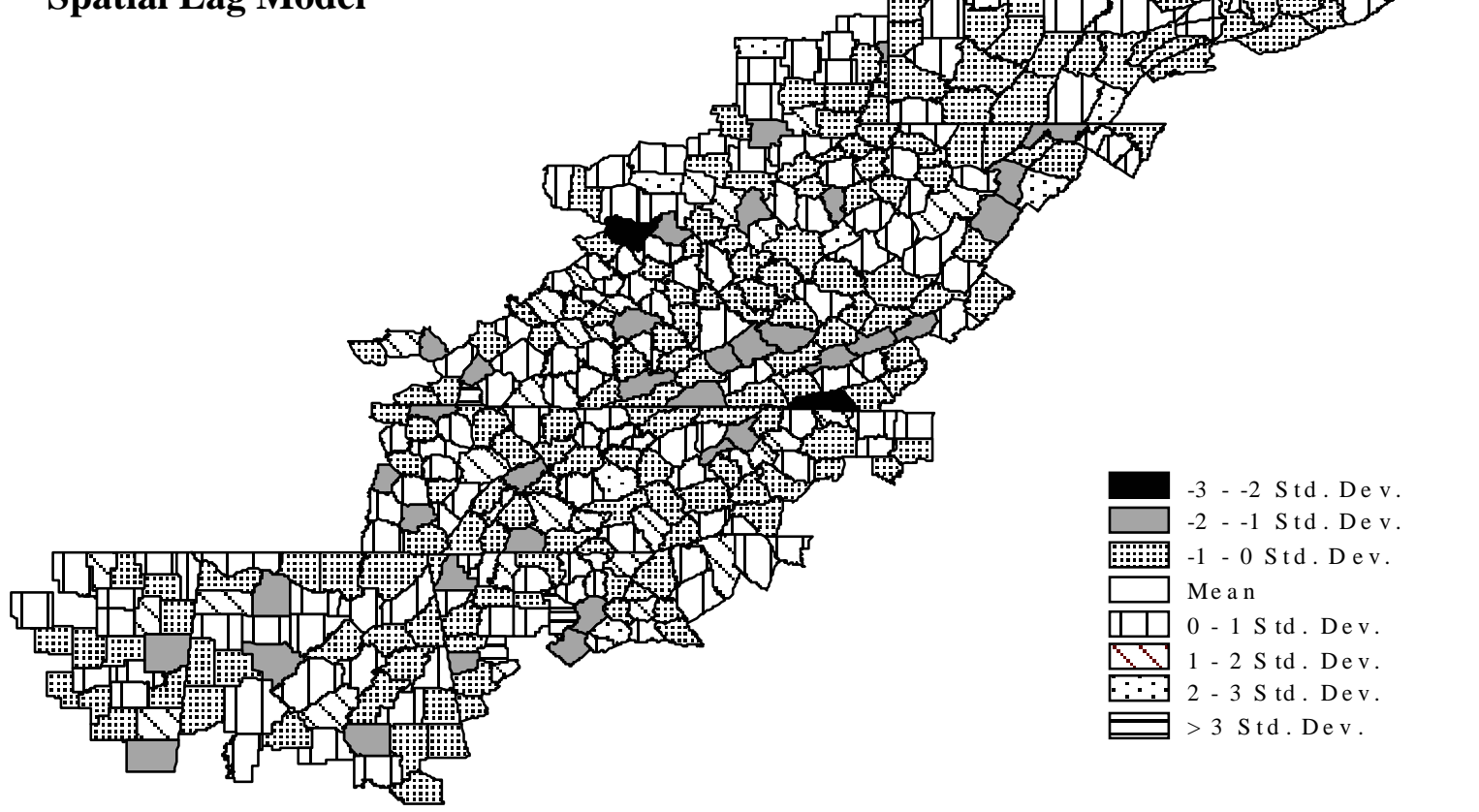




\section{$\underline{\text { References }}$}

Aaron, H.J. (1990), Discussion of 'Why is Infrastructure Important?' in A. Munnell, ed. Is There a Shortfall in Public Capital Investment? Federal Reserve Bank, Boston, pp. 51-63. Anderson, A. E., Anderstig, C., and Harsman, B. (1990) 'Knowledge and communications infrastructure and regional economic change,' Regional Science and Urban Economics, vol. 20, pp. 359-76.

Anselin, L. (1988) Spatial Econometrics: Methods and Models, Kluwer Academic Publishers, Dordrecht, The Netherlands.

. (2001) 'Spatial effects in econometric practice in environmental and resource economics,' American Journal of Agricultural Economics, vol. 83, no. 3, pp.705-710.

. (2003) 'Spatial externalities, spatial multipliers and spatial econometrics', International Regional Science Review, vol. 26, no. 2, pp. 153-166(14).

Anselin, L. and Rey, S. (1991), 'Properties of tests for spatial dependence in linear regression models’, Geographical Analysis, vol. 23, pp. 112-31.

Appalachian Regional Commission (2003), http://www.arc.gov.

Aschauer, D. A. (1989a) 'Is public expenditure productive?,' Journal of Monetary Economics, vol. 23, no.2, pp. 177-200.

. (1989b) 'Public investment and productivity growth in the Group of Seven,'

Economic Perspectives, vol. 13, no. 5, pp. 17-25.

. (1993) 'Genuine economic returns to infrastructure investment,' Policy Studies

Journal, vol. 21, pp. 380-390.

Banister, D. and Berechman, J. (2000) Transport Investment and Economic Development, UCL Press, London, UK. 
Baum, H. and Behnke, N.C. (1997) 'Der volkswirtschaftliche Nutzen des Strassenverkehrs, Schriftenreihe des Verbandes der Automobilindustrie e.V. (VDA), 82, VDA, Frankfurt am Main.

Benirschka, M. and Binkley, J.K. (1994) 'Land price volatility in a geographically dispersed market,' American Journal of Agricultural Economics, vol. 76, no.2, pp. 185195.

Blum, U. (1982) 'Effects of transportation investments on regional growth: A theoretical and empirical investigation,' Papers of the Regional Science Association, vol. 49, pp. 169-84.

Boarnet, M.G. (1998) 'Spillovers and the locational effects of public infrastructure,' Journal of Regional Science, vol. 38, pp. 381-400.

Briggs, R. (1980) 'The impact of interstate highway system on non-metropolitan growth,' U.S. Department of Transportation, Office of University Research, Washington D.C.

Brueckner, J.K. (2003) 'Strategic interactions among governments: An overview of empirical studies', International Regional Science Review, vol. 26, no. 2, pp. 175-188(14). Bruinsma, F.R., Rienstra, S.A. and Rietveld, P., (1997) 'Economic impacts of the construction of a transport corridor: A multi-level, multi-approach case study of the A1 highway in the Netherlands, Regional Studies, vol. 31, pp., 391-402.

Burridge, P. (1980) 'On the Cliff-Ord test for spatial autocorrelation,' Journal of Royal Statistical Society, vol. B 42, pp. 107-8.

Chandra, A. and Thompson, E. (2000) 'Does public infrastructure affect economic activity? Evidence from rural interstate highway system,' Regional Science and Urban Economics, vol. 30, no. 4, pp. 457-490. 
Chernoff, M. (1978) 'Density as a determinant of highway impacts', Transportation Research Record 686, pp. 4-9.

Corsi, T.M. (1974) 'A multivariate analysis of land use change: Ohio Turnpike interchanges, Land Economics, vol. 50, pp. 232-41.

Deno, K.T. (1988) 'The effect of public capital on U.S. manufacturing activity: 1970-1978', Southern Economic Journal, vol. 2.

Epps, J.W. and Stafford, D.B. (1974) 'Interchange development patterns on interstate highways in South Carolina,' Paper presented at the $53^{\text {rd }}$ Annual Meeting of Highway Research Board, Washington, D.C.

Fernald, J. (1993) 'How productive is infrastructure? Distinguishing reality and illusion with a panel of U.S industries,' Federal Reserve Board Discussion Paper.

. (1999) 'Roads to prosperity? Assessing the link between public capital and productivity,' American Economic Review, vol. 89, no. 3, pp. 619-638.

Garcia-Mila, T. and McGuire, T. J. (1992) 'The contribution of publicly provided inputs to states’ economies’, Regional Science and Urban Economics vol. 22, no.2, pp., 229 - 42.

Holtz-Eakin, D. (1988) 'Private output, government capital, and the infrastructure crisis,' Discussion paper no. 394, Columbia University. - (1994) 'Public-sector capital and the productivity puzzle,' Review of Economics and Statistics, vol. 76, pp.12-21.

Holtz-Eakin, D. and Schwartz, A.E. (1995) 'Spatial productivity spillovers from Public infrastructure: Evidence from state highways,' International Tax and Public Finance vol.2, no.3, pp. 459-68. 
Hulten, C. R. and Schwab, R.M., (1991) 'Is there too little public capital? Infrastructure and economic growth,' American Enterprise Institute Discussion Paper, February issue. Humphrey, C.R. and Sell, R.R. (1975) 'The impact of controlled access highways on population growth in Pennsylvania nonmetropolitan communities, 1940-1970', Rural Sociology, vol. 42, pp. 332-43.

Isserman, A. M., Rephann, T.J. and Sorenson, D.J. (1989) 'Highways and rural development: Results from quasi-experimental approaches’, West Virginia University, Regional Research Institute Working Paper 8907.

Jorgenson, D. (1991) 'Fragile statistical foundations: The macroeconomics of public infrastructure investment,' American Enterprise Institute Discussion Paper, February issue.

Kelejian, H.H. and Robinson, D.P. (1992) 'Spatial Autocorrelation: a new computationally simple test with an application to per capita county policy expenditures,' Regional Science and Urban Economics, vol. 22, pp. 37-31.

Kelejian, H.H. and Robinson, D.P. (1993) 'A suggested model of estimation for spatial independent models with autocorrelated errors, and an application to a county expenditure model', Papers in Regional Science, vol. 72, pp. 297-312.

Kocherlakota, N. and Yi, K. (1992) 'The long-run effects of government policy on growth rates in the United States,' University of Iowa/ Rice University Mimeo, September issue. Krugman, P. (1991) Geography and Trade, MIT Press, Cambridge, Massachusetts.

Krugman, P. and Venables, A.J. (1995) 'Globalization and the inequality of nations,' Quarterly Journal of Economics, vol. 110, pp. 857-880. 
Lichter, D.T. and Fuguitt, G.V. (1980) 'Demographic response to transportation innovation: the case of the interstate highway,' Social Forces, vol. 59, pp. 492-511.

Lynde, C. and Richmond, J. (1992), 'The role of public capital in production,' Review of Economics and Statistics, vol. 74, pp. 37-44.

Martin, P. (1999) 'Public policies, regional inequities and growth,' Journal of Public Economics, vol. 73, pp. 85 -105.

Mason, J. B. (1973) 'Highway interchange land use development,' Growth and Change, vol. 3, pp. 38-43.

McMahon, W.W. and Chang, S. (1991) 'Geographical cost of living differences: Interstate and Intrastate, update 1991,' MacArthur/Spencer Series Number 20, Center for the Study of Educational Finance, Illinois State University.

Mikelbank, B.A. and Jackson, R.W. (1999) 'Equity vs. efficiency: Public capital investment in Ohio, 1988-1992. Professional Geographer, vol. 51, pp. 196-209. . (2000) 'The role of space in public capital research,' International Regional Science Review, vol. 23, no. 3, pp. 235-258.

Moomaw, R.L, Mullen, J.K. and Williams, M (1996) 'Public capital stocks and state variations in productive efficiency within the U.S. manufacturing sector,' Journal of Policy Analysis and Management, vol. 15, pp. 51-67. . (1995) 'The interregional impact of infrastructure capital,' Southern Economic Journal, vol. 61, pp. 830-845.

Moon, H. E. (1988) 'Interstate highway interchanges as instigators of nonmetropolitan development,' Transportation Research Record 1125, pp. 8 - 14. 
Morrison, C.J. and Schwartz, A.E. (1996) 'State infrastructure and productive performance,' American Economic Review, vol. 86, pp. 1095-111.

Munnell, A.H. (1990a) 'Why has productivity growth declined? Productivity and public investment,' New England Economic Review, January-February, pp. 3-22. . (1990b) 'How does public infrastructure affect regional economic performance', New England Economic Review, September-October: 11 - 32. . (1990c) 'Is there a shortfall in public investment?,' Ed. Alicia H. Munnell. Conference Series No. 34, Federal Reserve Back of Boston.

Nadiri, M.I. and Mamuneas, T.P. (1994) 'The effects of public infrastructure and R\&D capital on the cost structure and performance of U.S. manufacturing industries,' Review of Economics and Statistics, vol. 76, pp. 22-37.

Nijkamp, P. (1986), 'Infrastructure and regional development: A multidimensional policy analysis,' Empirical Economics, vol. 11, pp. 1 -21.

Puga, D. (2002) ‘European regional policies in light of recent location theories,' Journal of Economic Geography, vol. 2, Issue 4, pp. $372-406$.

Rietveld, P. and Boonstra, J. (1995) 'On the supply of network infrastructure: Highways and railways in European regions,' The Annals of Regional Science, vol. 29, pp. 207 220.

Rephann, T. (1993) 'A study of the relationship between highways and regional economic growth and development using quasi-experimental control group methods,' Ph.D. Dissertation, West Virginia University. 
Rephann, T. and Isserman, A. (1994) 'New highways as economic development tools: An evaluation using quasi-experimental matching methods,' Regional Science and Urban Economics, vol. 24, pp. 723-751.

Rubin, L.S. (1991) 'Productivity and the public capital stock: Another look,' Federal Reserve Board Discussion Paper, May issue.

Schultze, C.L. (1990) 'The Federal budget and the nation's economic health,' in Setting National Priorities: Policies for the Nineties, Ed. Henry J. Aaron. Brookings Institution, pp. 19-64.

Tatom, J.A. (1991a) 'Should government spending on capital goods be raised?,' Federal Reserve Bank of St. Louis Review, March-April issue, pp. 3-15. . (1991b) ‘Public capital and private sector performance,' Federal Reserve Bank of St. Louis Review, May-June issue, pp. 3-15. . (1993) 'Paved with good intentions: The mythical national infrastructure crisis,' Policy Analysis, August Issue, Cato Institute.

Transportation Statistics Annual Report (2001), Bureau of Transportation Statistics, U.S. Department of Transportation, Washington D.C.

Twark, R.D., Eyerly, R., and Nassi, T. (1980) 'Quantitative technique for estimating economic growth at non-urban limited access highway interchanges,' Transportation Research Record, no. 747. pp. 12-19.

Venables, A.J. and Gasiorek, M. (1999) 'The welfare implications of transport improvements in the presence of market failures,' report to SACTRA, Department of the Environment, Transport and the Regions, London. 
Vickerman, R.W., Speikermann, K., and Wegener, M. (1999) 'Accessibility and regional development,' Regional Studies, vol. 33, pp. 1-15.

Vickerman, R.W. (2000) 'Economic growth effects of transport infrastructure,' Jahrbuch fur Regionalwissenschaft, vol. 20, pp. 99-115.

Wheat, L.F. (1969) 'The determinants of 1963-77 regional manufacturing growth: Why the south and west grow,' Journal of Regional Science, vol. 26, pp. 635-59.

Williams, M. and Mullens, J.K. (1998) 'Highway capital spillovers and interstate manufacturing activity,' International Journal of Transport Economics, vol. 25. no. 3, pp. 287-297. 


\section{Chapter 3}

The Effect of Highway Capital on Output in Appalachia: Application of Spatial Autoregressive Models in Causality Analysis 


\title{
The Effect of Highway Capital on Output in Appalachia: Application of Spatial Autoregressive Models in Causality Analysis
}

\author{
Samia Islam \\ Department of Economics \\ West Virginia University \\ Morgantown, WV 26506 \\ Phone: (304) 293-2166 \\ Email:saislam@mail.wvu.edu.
}

\begin{abstract}
Public works projects, such as highways, play an important role in stimulating economic growth, through the injection of public capital as well as through the creation of access to formerly isolated locations for firms and households. These effects can get transmitted across counties that either have direct access to the projects or share borders with counties that do since space is continuous. Therefore, it is informative to investigate the positive spatial externalities (i.e., spatial spillovers) of public capital investment in highways on regional output. In this paper, I present a spatial model selection and estimation method within a production function framework, and then apply the selected spatial model to analyze this spatial spillover process. The last section of the paper examines the causality between output and highway capital stock using a twoequation spatial autoregressive model and finds evidence of causation from highway capital stock to output but does not find conclusive evidence of causality in the reverse direction.
\end{abstract}

JEL Classification: R11, R42, C11, C49

Keywords: Spatial Spillovers, Highway Capital, Output, Causality 


\subsection{Introduction}

The objective of highway investment is often to either stimulate a region's growth

or to accommodate the needs of an already growing region. In the first case, due to increased access away from the congested cores, firms relocate to the suburbs, and, gradually, people follow jobs. This causes peripheral regions to develop. In the latter case, growing cities, plagued by congestion, demand more roads and cause the city to expand.

Highways increase connectivity between regions, increasing the accessibility to both labor and capital, which eventually can translate into regional economic growth. All economic activity occurs across space that is continuous. Development in a particular area, therefore, is likely to cause positive and/or negative externalities for its neighbors. Geographers have long been concerned about such spatial interdependence but only recently has space enjoyed similar attention in economic analysis.

In this paper I investigate the extent of such spatial externalities, also referred to as spatial spillovers, of highway investment on output in the presence of spatial autocorrelation. Accounting for spatial interdependence in analyzing the attributes of transportation services is necessary to avoid biased results and to assess the benefits of long-term and costly public highway investments. As an application of spatial estimation methods, this study also examines the direction of causality between highway investment and output. Although some causality studies have focused on public capital and growth, none looked at causality between highways and output, especially after accounting for spatial interdependence or spatial autocorrelation.

The paper proceeds with a review of relevant literature in Section 3.2. The methodology is explained in detail in Section 3.3. Section 3.4 lists a description of the 
data and details of various data sources. Sections 3.5 and 3.6 discuss the spatial model selection and estimation process. Section 3.7 presents the methodology and findings of the causality analysis. Section 3.8 provides a detailed discussion of the empirical results, followed by concluding remarks in Section 3.9. All tables are included in a separate section following this chapter.

\subsection{Literature Review}

The mountainous Appalachian terrain and the economic condition of its constituent counties make a study of the region's highway capital effectiveness quite compelling. Williams and Mullen (1998) have found that highway capital has the strongest positive cross-state spillovers in the southern states. They conclude that higher highway investment in the southern states would provide the region with a competitive edge in manufacturing. Others researchers, looking at different geographical regions, found that southern and mountain states gain the most from new highways (Briggs 1980; Munnell 1990a). These results have relevance for the Appalachian region due to the ruggedness of the terrain and its geographic location.

The primary purpose of this paper is to determine whether spatial econometric analysis more accurately captures the impact of highway capital in Appalachia's economic performance. Generally, standard econometric studies trying to establish the statistical link between aggregate infrastructure investment and growth in GDP have, at times, found suspiciously high rates of return of up to 60 percent. These analyses, and the claimed strong causality, have been scrutinized extensively leading to two main criticisms. The first concerns whether the simple relationship between output (GDP) and input (rate of investment in infrastructure) is influenced by factors not included in the 
analysis. The second addresses the direction of causality, i.e., whether growth leads to additional infrastructure investment, or whether highway investment leads to growth. As an application of the spatial econometric analysis carried out in this essay, I also address this second issue of causality between highway capital and output.

Most studies trying to determine the impact of public capital have looked at the sector in the aggregate. A few have considered the impact of transportation networks on regional productivity and output. Regional production function studies usually have found transportation infrastructure to be an important determinant of regional output (Mera 1975; Blum 1982; Nijkamp 1986; Deno 1988; Anderson et al. 1990, Lynde and Richmond 1992), though some have found the effect to be rather small, even after controlling for state effects (Garcia-Mila and McGuire 1992; Munnell 1990b). The general conclusions reached are that public capital has some impact on economic growth, private capital and labor productivity, but the magnitude and significance of these effects are not clear (Munnell 1992).

Aschauer (1990) showed that public capital "Granger causes” output. Over the last decade, however, the new economic geography (NEG) literature (Krugman 1991; Krugman and Venables 1995; Martin 1998; Venables and Gasiorek 1999; Puga 2002) has emphasized that public infrastructure's effect depends critically on a region's industrial composition. NEG does not support the use of Aschauer's single-equation approach, which does not differentiate between different sectors of the economy.

Research regarding productivity spillovers of state highways has found only limited, though distinct, empirical evidence that highways (more generally, public 
capital) have cross-state effects on productivity and output ${ }^{12}$ (Holtz-Eakin and Schwartz 1995; Moomaw, Mullen and Williams 1995). Kelejian and Robinson (1997) looked at both productivity and infrastructure spillovers across states but did not find conclusive evidence of the latter.

While less industrialized, densely populated metropolitan counties are generally found to gain the most from highway and interchange development (Humphrey and Sell 1975; Chernoff 1978; Briggs 1980; Lichter and Fuguitt 1980; Isserman et al. 1989, Rephann 1993), counties adjacent to highway-impacted counties actually lose due to transfer of resources to the impacted county (Rephann and Isserman 1994; Boarnet 1998). Rural interstate highways appear to affect the spatial allocation of economic activities and raise the level of activity in counties through which they pass at the expense of economic activities in adjacent counties (Chandra and Thompson 2000). In light of these findings and the substantial investments that went into the ADHS, it is interesting to examine the effect of highways on predominantly rural Appalachia, and to determine whether highway capital impacts Appalachian output or vice versa.

Although substantial research has been devoted to causality studies between university research and knowledge spillovers (Anselin et al. 2000), no study has examined direction of causality between highway capital spillovers and regional growth, in the presence of spatial autocorrelation. Spatial analysis is attracting increasing attention from economists. In recent years, regional economists have begun to assimilate spatial analysis methodologies more commonly applied by geographers. Anselin (1988, 2001, 2003) has made major contributions to spatial econometric theory. Applying spatial

\footnotetext{
${ }^{12}$ Most researchers have found that the role of public capital is reduced substantially by accounting for cointegration and nonstationarity (Harmatuck 1996; Haughwout 1996).
} 
econometric methodology, the effect of public capital has been found to range from positive to negative and everything in between, including no role at all (Mikelbank and Jackson 2000). This paper draws heavily on Anselin's work for research methodology, especially in specifying and quantifying spatial externalities.

The studies cited above have drawn attention to public infrastructure's importance in promoting economic growth and private capital productivity. Their findings indicate that the growth effect of public capital expansion is influenced by the annual (percent) increase in the public capital stock rather than the size of the investment. This means that a large investment in public infrastructure is bound to have an insignificant impact on economic growth if it constitutes a negligible addition to the in-place public infrastructure stock. For example, a massive investment in a new transport link may yield insignificant growth effects if this link constitutes only a small proportion of a well-developed network.

\subsection{Methodology}

Using a production function approach, first I examine the nature and direction of the spatial spillovers from public highway investment. Aschauer (1989) showed that public infrastructure investment yielded substantial returns. Subsequent papers, however, pointed out that these results are subject to simultaneity bias and spurious correlation. After controlling for these two problems econometrically, public investment shows a much more subdued impact on output growth. This simultaneity (reverse causality) and spurious correlation may also apply to returns to road networks, apart from the spatial autocorrelation that underlies regional economic models. 
A structural macro model provides one way to model the spatial spillovers of public highway investment. I will follow Boarnet’s (1998) standard production function approach, treating each county as a single entity whose output depends on public (highway) infrastructure, capital and labor:

$$
Q=f(L, K, G, H W Y, S H W Y)
$$

where $Q$ is output, $G$ and $K$ are public and private sector capital stock respectively, $L$ is labor, and $H W Y$ represents highway capital. SHWY is the spillover variable. This specification is in keeping with the spillover variable constructed by Yilmaz, Haynes and Dinc (2002) for their study of telecommunication networks. The neighbors' highway capital variable $(S H W Y)$ is calculated as:

$$
S H W Y=W H W Y_{j}=\text { all (geographic) neighbors, }
$$

where each element of $W, \mathrm{w}_{i},=1 \quad$ if states $\mathrm{i}$ and $\mathrm{j}$ share a common border, and

$$
=0 \quad \text { otherwise }
$$

The specific model employed for the analysis is:

$$
\log (Q)=\alpha_{o}+\alpha_{1} \log (L)+\alpha_{2} \log (K)+\alpha_{3} \log \left(G_{-1}\right)+\alpha_{4} \log \left(H W Y_{-1}\right)+\alpha_{5} \log \left(\sum W H W Y_{-1}\right)+\varepsilon
$$

where the subscript, ${ }_{-1}$, indicates a one-period (five year) lag.

Spatial dependence may lead to model misspecification, while spatial heterogeneity can cause instability of behavioral relationships (Anselin 1988, 2002, 2003). We need additional tests to address spatial interaction issues and to assess robustness of our estimates. Spatial correlation or dependence within a regional economic model often results from an omitted variable related to the connectivity of neighboring regions (Kelejian and Robinson 1997). Proper model specification would quite likely reduce or eliminate spatial dependence. 
A standard assumption of a basic linear regression model is that the error terms are i.i.d. ${ }^{13,14} \mathrm{~A}$ well-known test for spatial autocorrelation in the regression error term is Moran's I (Ord 1975). I apply this test to the residual values for each year. Another source of spatial dependency is geographic proximity. The county-level data are tested for spatial autocorrelation using Moran's I statistic with a contiguity based on a fivenearest-neighbor spatial weights matrix. ${ }^{15}$

\subsection{Data}

County output data are derived by apportioning state product to counties based on total county personal income. This is the methodology used by the Southern California Association of Governments to estimate county product within their region. Gross state product data are available from the U.S. Bureau of Economic Analysis (BEA). Labor force data are from the U.S. Bureau of Labor Statistics (BLS) as published in the 1998 USA Counties data CD released by the U.S. Bureau of the Census.

Public capital stock data are not available by county. We can estimate this variable by apportioning the state totals to counties. The state level public capital data are from Munnell (1990a), as well as the apportioning method, which also follows Costa, Elson and Martin (1987). To estimate county public capital, we used the ratio of county total direct government expenditure (obtained from Census of Governments) to the state total for each year and apportioned the total state public capital stock to the corresponding counties. Yilmaz, Haynes and Dinc (2002) have found that the

\footnotetext{
${ }^{13}$ Independent and identically distributed.

${ }^{14}$ With spatial autocorrelation: $E\left(\varepsilon_{i} \varepsilon_{j}\right) \neq 0$.

${ }^{15}$ All econometric analysis was done in MATLAB using programs from the spatial econometrics toolbox, courtesy of Professor James P. LeSage, University of Toledo. Available for free download at http://spatialeconometrics.com/.
} 
government direct capital expenditures for all states and the United States follow the same trend as state and national public capital stock. This confirms that each county's share in state capital expenditure is a good proxy for the size of its public capital.

It is perhaps more problematic to estimate private capital stock for each year, by county. Manufacturing sector value added and wage and salary compensation data are available at the state and county level from the U.S. Bureau of the Census. ${ }^{16}$ We can estimate county private capital stock $\left(K_{i}\right)$ by using the following procedure (Yilmaz, Haynes and Dinc 2002):

$$
K_{i}=\left[\left(V A D D_{i}-W S_{i}\right) /\left(V A D D_{n}-W S_{n}\right)\right] K_{n}
$$

where $i$ indexes counties and $n$ indexes the state. VADD is total value added (output) and WS is wage and salary expenditures for private manufacturing industries. So, VADD WS represents returns to private capital indicating the size of the private capital stock in each county. ${ }^{17}$

State and local highway capital expenditure data come from the Federal Highway Administration (FHWA) and the federal highway capital expenditure data by county are from the Census of Governments. Capital investments in the current period are not expected to affect current output. Therefore, five-year lagged public, private and highway capital stock data are used in the model in order to allot a reasonable time for the effects of these investments to be reflected in current output. Highway and public capital stock data are available for 1972, 1977, 1982 and 1987. All other data are available for the years 1977, 1982, 1987 and 1992.

\footnotetext{
${ }^{16}$ USA Counties Data CD.

${ }^{17}$ We are using data from private manufacturing industries to represent total private capital stock, which overlooks private capital in other industries, such as mining, construction, etc. The primary reason for omitting the other sectors from our analysis was data unavailability.
} 


\subsection{Spatial Model Specification}

Although theory suggests the presence of spatial autocorrelation in the data, we need to first run a standard OLS regression and carry out a Moran's I test. A high Moran's I statistic of $11.08092^{18}$ allows us to reject the null hypothesis of no spatial autocorrelation. An array of different spatial specifications with associated estimators and tests has been developed within the ambit of spatial econometrics. This led to issues of model comparison and model choice, measuring relative merits of alternative specifications and then using appropriate criteria to choose the 'best' model or relative probabilities.

The spatial lag model is the specification of the spatial autoregressive (SAR) model most commonly applied in cases where theory indicates that the spatial process is more than just a 'nuisance' effect. It specifies spillover in the $\boldsymbol{y}$ variable rather than the disturbances:

$$
y=\lambda W y+X \beta+u \quad|\lambda|<1
$$

where $\boldsymbol{y}$ is an $\mathrm{n}$ by 1 vector of observations on a dependent variable, $\boldsymbol{X}$ is an $\mathrm{n}$ by k matrix of observations of explanatory variables, $\beta$ is a $\mathrm{k}$ by 1 vector of regression coefficients, $\lambda$ is the spillover parameter and $\boldsymbol{u}$ is an $\mathrm{n}$ by 1 vector of random disturbance terms. Defining $\boldsymbol{P}=(\boldsymbol{I}-\lambda \boldsymbol{W})$ and $\boldsymbol{y}^{*}=\boldsymbol{P} \boldsymbol{y}$, the relevant likelihood function is:

$$
f u(\lambda)=\frac{1}{p(y)} \frac{1}{D} \cdot \Gamma \frac{(n-2)}{k} \cdot \frac{1}{(2 \pi)^{(n-k) / 2}} \cdot \frac{1}{\left|X^{\prime} X\right|^{1 / 2}} \int|P| \frac{1}{s^{2(n-k) / 2}} d \lambda
$$

where $\boldsymbol{s}^{2}$ is the residual sum-of-squares of the regression of $\boldsymbol{y}^{*}$ on $\boldsymbol{X}$. Note that $\boldsymbol{X}$, and therefore, $\left|\boldsymbol{X}^{\boldsymbol{X}} \boldsymbol{X}\right|^{-1 / 2}$ are not transformed at all in the spatial-lag model. Since these terms do not vary with $\lambda$, they can be taken outside the integral.

\footnotetext{
${ }^{18}$ The null hypothesis is rejected if the value of the Moran's I statistic exceeds 1.96.
} 
The Spatial Lag model is a constrained form of the general spatial autoregressive model with autoregressive disturbances:

$$
y=\lambda W_{1} y+X \beta+W_{2} X \gamma+e
$$

where for a vector of random error terms:

$$
\begin{gathered}
\boldsymbol{u}=\lambda \boldsymbol{W}_{3} \boldsymbol{u}+\boldsymbol{e} \\
\text { or, } \boldsymbol{e}=\left(\boldsymbol{I}-\lambda \boldsymbol{W}_{3}\right) \boldsymbol{u}
\end{gathered}
$$

and, where $\boldsymbol{e}$ is an $\mathrm{n}$ by 1 vector of i.i.d. error terms with variance of $\sigma^{2}$.

Substituting equation 8 into equation 7, we get:

$$
y=\lambda W_{1} y+X \beta+W_{2} X \gamma+\left(I-\lambda W_{3}\right) u
$$

This general specification includes spillovers from the dependent variable $(\lambda \boldsymbol{W y})$, spatial spillover from the independent variable ( $\boldsymbol{W} \boldsymbol{X} \boldsymbol{\gamma})$, as well as the disturbances.

In equation 9 , if $\boldsymbol{W}_{3}$ is a matrix of zeros, implying no spatial autocorrelation in the disturbances, then we have a spatial autoregressive model, where spatial spillovers affect the dependent and independent variables but not the error terms:

$$
y=\lambda W_{1} y+X \beta+W_{2} X \gamma+u
$$

If $\boldsymbol{W}_{2}$ and $\boldsymbol{W}_{3}$ are zero matrices, then equation 9 is reduced to equation 4 , which is the spatial lag model. If both $\boldsymbol{W}_{\mathbf{1}}$ and $\boldsymbol{W}_{\mathbf{2}}$ are zero matrices (i.e., no spillovers from the dependent and independent variables), but $\boldsymbol{W}_{3}$ is non-zero, we have the spatial error model (SEM).

For computational simplicity, it is generally assumed that $\boldsymbol{W}_{\mathbf{1}}=\boldsymbol{W}_{\mathbf{2}}=\boldsymbol{W}_{\mathbf{3}}=\boldsymbol{W}$, where the $\mathrm{W}$ matrix is non-zero. Now, if we rewrite equation 9, we get:

$$
y=\lambda W y+X \beta+W X \gamma+(I-\lambda W) u
$$


This is the typical general specification of the spatial autoregressive model with autoregressive disturbances. Since the $\boldsymbol{W} \boldsymbol{X}$ is a transformation of exogenous variables, these additional components can simply be added to $\boldsymbol{X}$ to define an extended set of $2 \mathrm{k}-1$ columns (constant is not lagged). This model, denoted as $M_{G E N}$, can be estimated using the same expression as for the spatial spillover (or spatial lag) model, with appropriate redefinition of $\boldsymbol{X}$ and the marginal likelihood for this model as $p\left(y \mid M_{G E N}\right)$.

The spatial autoregressive model can be derived from the standard OLS specification as follows:

$$
\begin{aligned}
y & =X \beta+u \\
\text { or, }(I-\lambda W) y & =(I-\lambda W) X \beta+(I-\lambda W) u \\
\text { or, } \quad y & =\lambda W y+X \beta+W X(-\lambda \beta)+u-\lambda W u \\
& =\lambda W y+X \beta+W X(-\lambda \beta)+e
\end{aligned}
$$

This is the general form constrained such that $\gamma=(-\lambda \beta)$, which is known as the common factor restriction. Tests of the common factor restriction, using either Wald tests on the general form or a likelihood ratio test, have been constructed and applied for spatial econometric models (Bivand 1984, Burridge 1981). The $W$ matrix used in the analysis is the standardized contiguity-matrix constructed using the nearest neighbor criterion (set to five) using the $\mathrm{X}-\mathrm{Y}$ coordinates of all regional county centroids.

\subsection{Model Selection}

Model choice initially depends on the underlying theory. In our case, theory suggests the spatial autoregressive model because the spatial error model (SEM) treats the spatial process as a nuisance. In a classic example of spatial error dependence, Benirschka and Binkley (1994) found that the less favorably located plots (with respect to 
the location of the market) were more affected by land price changes than those located near the market. In regional or local markets, therefore, among land plots with the same characteristics, the more valuable land is located closest to the market. In this essay, however, spatial autocorrelation can not be looked at as a nuisance since highways have a direct impact not only on people's mobility but also on regional accessibility. In the analysis that follows, I have applied both models to test whether empirical results support theory. To select the appropriate model, I conducted the relevant robust tests as suggested by Anselin and Bera (1998).

The dependent variable in the regression equation is gross county output derived from apportioning gross state output to counties using the total personal income ratios for each county. Explanatory variables are lagged public capital stock, private capital, total employment, and lagged highway capital stock. All current period data refer to 1992 and the lagged data are from 1987. The results are presented in Table 3.1. We expect all of the independent variables will have positive signs. Highway capital stock in neighboring counties (shwy) can, however, have a negative sign if a backwash effect is present, i.e., highway networks in neighboring counties draw labor and private capital away. The spatial regression analysis was carried out using maximum likelihood estimation methods.

Given the high Moran's I statistics (11.81) from the OLS regression, I first apply a spatial error model (SEM). I find that private capital and neighboring highway capital stock do not have significant estimated coefficients but own-highway capital stock is highly significant at the $5 \%$ level. Since these coefficients refer to elasticities, we can conclude that adding a little more highway capital to an area with a large highway network does not do much to output (Table 3.1). A one percent increase in highway 
capital only results in a two-hundredths of one percent increase in output. Alternately, a highway that might increase highway capital by 500 percent in some rural county would increase output by 10 percent. All other estimated coefficients are significant and have expected signs. Both labor and public capital stock are positive and significant. The estimated spatial spillover coefficient, $\lambda$, which measures the diffusion of output's impact through space, is also highly significant and substantial.

The large magnitude of the spillover parameter is due to bias arising from incorrectly attributing the spatial autocorrelation process to the disturbances. Theoretically, a spatial process underlies the data when one county's economic performance is transmitted to its neighboring counties through space. On the contrary, spatial errors treat the spatial interdependence as a 'nuisance' effect rather than a structural spatial process.

Some of the obvious problems of the spatial error model are rectified when the spatial autoregressive (SAR) model is applied. In the SAR model, private capital is significant at the $1 \%$ level. Also, neighbors' highway capital stock is now significant at the 5\% level, but negative, implying a backwash effect of neighbors' highway capital investment. All other parameter estimates have the expected signs. Although still highly significant, spatial spillovers $(\lambda)$ are not as pronounced as in the spatial error model (SEM), implying that a little more than half of a one percent increase in output can be attributed to spatial spillovers from neighboring counties. This supports the theory that the appropriate spatial model reduces (or, eliminates) spatial autocorrelation. In a joint 
specification-robust test ${ }^{19}$ using LM error and LM lag statistics to choose between Spatial Error and Spatial Lag model, the model with the highest significance (lower p-value) is chosen. In this case, the Spatial Lag model has the lowest p-value (highest significance) and is, therefore, selected.

\subsection{Direction of Causation}

Once we have established the nature and sign of the highway investment spillovers, we can test for the direction of causality using spatial autoregressive techniques. The analysis uses a two-stage spatial autoregressive model containing one equation for output with lag of highway capital stock as regressor, and another for highway capital stock, with lag of output as regressor. I test the null hypothesis that the coefficients of the output variable equal zero in the equation for highway capital stock, and vice versa.

Given time series data unavailability, the methodology used in this essay can substitute for a standard Granger causality analysis. Usually causality analysis with time series data involves Granger’s causality specification. Such methods cannot be applied to cross section datasets or even panels with less than 30 years of data. The model used here employs a similar methodology. The two-equation SAR model follows standard VAR causality methodology with lags of the dependent variable on the RHS. The first equation (output equation, with lagged highway capital as regressor) determines causation from highways to output and the second equation (highway equation, with highway capital as

\footnotetext{
${ }^{19}$ The test was carried out in Spacestat, an econometric software package with geospatial analytical abilities developed by Professor Luc Anselin, University of Illinois at Urbana-Champaign.
} 
the dependent variable and lagged output as a regressor), determines causation from output to highways.

In the highway equation, a different set of exogenous variables is used because some of the exogenous variables of the output equation, i.e., labor and private capital, are not relevant determinants of highway capital investment. The exogenous variables included in the highway capital equation are population growth, land area, ${ }^{20}$ lagged ${ }^{21}$ public capital (excluding highway capital), lagged output, annualized output growth rate for 1977-1982, own lagged highway capital and neighbor’s lagged highway capital. Land area and population data are from the U.S. Bureau of the Census. Since I did not have highway and public capital stock data for 1992, for the causation analysis, I used 1987 as the current period and 1982 as the lagged period.

Costly highway projects would primarily be influenced by a region’s population and output growth trends. The land area of each county is also an important determinant because it accounts for the distance between counties and the extent of isolation from neighbors. In the absence of data on governmental policy interventions, lagged public capital would account for the existing amenities of a county or state that affect its desirability as a location choice, as well as presence of major centers of government employment. Lagged highway capital accounts for the amount of highway network already in place in these counties.

Applying SAR methodology, I find that the parameter for highway capital stock in the output equation is positive and significant, i.e., we can reject the null hypothesis of

\footnotetext{
${ }^{20}$ Census 1980, U.S. Bureau of the Census.

${ }^{21}$ All lags refer to values from five years earlier, i.e., when current period is 1987, the lag refers to 1982. The five-year lag is reasonable for projects such as highways that need time to be planned and constructed, and because their impact may not be felt for some years.
} 
a zero coefficient. On the other hand, in the highway equation, output is positive but insignificant (t-statistic of 0.8). We cannot, therefore, reject the null hypothesis that the coefficient of output is zero. In the latter equation, however, the presence of multicollinearity between public capital and output prevent us from drawing a definitive conclusion. A detailed explanation follows.

\subsection{Results}

From the model selection analysis, we can conclude that the SAR model is most appropriate in capturing highway capital's impact on county output. The standard OLS model is subject to omitted variable bias in the presence of spatial autocorrelation, which is clearly indicated by the high Moran's I statistic. As for the spatial error model, it does not find neighbors' highway capital stock or private capital to be significant. The SAR model finds negative and significant coefficient estimates for both private capital and neighbors’ highway capital stock. The negative coefficient of neighbors' highway capital stock is an interesting result because it suggests a backwash effect, i.e., highway network expansions in surrounding counties draw productive activity away. Also, the negative private capital coefficient is consistent with the economic shifts occurring in the region where manufacturing industries are on the decline and service sector industries are undergoing rapid growth.

In Table 3.2 we report the results from the causation analysis. In the output equation, all the RHS variables ${ }^{22}$ are significant at the $1 \%$ level except neighbor's highway capital, which is significant at the $10 \%$ level. The positive and significant lagged highway capital coefficient confirms that highway capital significantly affects output.

\footnotetext{
${ }^{22}$ All variables in both equations are in $\log$ form.
} 
The coefficients for labor and lagged public capital have positive signs while neighbor's highway capital and private capital have negative signs. The negative sign of the neighbors' highway capital stock implies that highway investment in surrounding counties can draw output away from a county, whereas investment in its own highways can exert a positive impact on its output.

At first glance, the negative sign of the private capital coefficient may cause concern. The private capital data used here, however, only accounts for the manufacturing capital stock in these counties. Given the nature of the private capital data we used and the regional industrial composition, therefore, the negative sign can be interpreted as an indicator of the rise of service sector activities in the region in the last two decades.

Other factors might also plausibly explain the negative sign for private capital. It could reflect crowding out of private capital due to increased public capital investments in the region. If lagged public capital crowds out current period private capital then the coefficient may be picking up these effects. Using lagged private capital as a regressor may help address this issue. Using lagged private capital instead of current period private capital as a RHS variable, however, does not mitigate the statistically significant negative sign for the coefficient of private capital.

The calculation of output, using the total personal income ratio in each county to apportion gross state product to counties, might also influence the capital stock outcome, especially its statistical significance in the case of 'distressed' counties. Transfer payments, one component of total personal income, tend to be relatively higher in poorer counties, due to income assistance payments. If private capital is less likely to move to 
these poor counties where high levels of public assistance payments prop up incomes, then transfer payments and total personal income could be negatively correlated. A simple correlation analysis between total personal income and transfers, however, finds evidence of positive and significant correlation. Further, total personal income and private capital stock are positively correlated for this Appalachian sample. While a complex multivariate correlation analysis would be necessary to answer this question completely, these correlations suggest that the negative sign of the private capital coefficient is not directly driven by transfer payments.

Belsey, Kuh and Welsch multicollinearity diagnostics ${ }^{23}$ indicate substantial multicollinearity between labor and public capital in the output equation. The effects of severe multicollinearity, however, are typically reflected in low t-statistics. Since the tstatistics for labor and public capital from the output regression are quite high, multicollinearity does not adversely influence the conclusions from the analysis. In the highway equation, presence of multicollinearity is less easily explained away.

In the highway equation, lagged output, although positive, is not significant. This would normally indicate that causation runs from highways to output, and not the other way around. Evidence of multicollinearity between public capital and output, however, renders this result inconclusive. Although the natural correlation between public capital and output is not entirely unexpected, I have tried to correct for the multicollinearity with a number of different specifications for the highway equation. One of these excluded lagged public capital as an RHS variable and found lagged output to be positive and highly significant. This specification, however, was not robust enough for our considerations since the highly significant output coefficient was most likely picking up 
the effects of a major omitted variable, i.e., public capital, which in this model represents all public infrastructure and amenities that make a location desirable for firms and households.

As expected, the strongest influence is from lagged highway capital and lagged public capital implying that if highway or public capital investment increases in the last period, then highway capital investment in the next period increases as well. Spatial spillovers are evident from the sign and size of the spillover parameter, $\lambda$, which is positive and significant (at the $10 \%$ level) in all of the model specifications I have tried.

Among the other variables, land area, population growth rate and output growth rate are not significant. We expect that if surrounding counties are investing in their highway capital stock, it will be beneficial for the county itself to expand its own highway network to strengthen its connection to the rest of the region. The sign of the neighbors' highway capital coefficient is in fact negative but not significantly different from zero. This may be due to the fact that the network effects are not being addressed separately in the model. Neighbors' highway capital is simultaneously capturing the negative backwash effect and the positive network effect, and in the process, the coefficient estimate is getting biased downward. Ideally, future extension of this paper would include the number of interchanges per highway mile as a RHS variable indicating the level of connectivity of each county but this data is not currently available.

Both equations are characterized by positive and significant positive spatial spillovers. The output and highway variables both have spatial processes embedded in them. About one tenth of a percent increase in a county's output (or, highway capital) can

\footnotetext{
${ }^{23}$ Belsey, Kuh and Welsch (1980).
} 
be attributed to the spatial diffusion of output (or, highway capital) from surrounding counties.

Table 3.3 reports the findings from another model specification using total public capital (including highway capital) as the dependent variable and all other exogenous variables from the highway equation as RHS variables. Population growth, lagged public capital and lagged output are highly significant and positive, while output growth rate, own highway capital and neighbors' output are negative and significantly different from zero at the $1 \%$ level. This implies that the counties that experienced the highest productivity growth during the previous five-year period did not benefit from an increase in total public capital. Also, those places that already had a relatively good highway network did not gain much from added total public capital. Furthermore, increased productive activity in neighboring counties drew public capital away from own county. Although once again, multicollinearity is still present between total public capital and output, the high t-statistics suggest that it does not adversely affect the conclusions.

\subsection{Conclusion}

In the 1960s and 1970s, during the planning and initial construction phase of the interstate highway system, highway impact studies enjoyed center stage. Many researchers and policy planners believed that highways could induce growth and prosperity. Others argued that the influence of highways is not large enough and that other factors have a greater contribution to decentralization and growth. Results from studies looking at highway infrastructure investment have rarely agreed on the magnitude and extent of their impact on regional economic performance. 
In my first essay, I have studied the distance decay of highway investment using a spatial autoregressive model. I applied the spatial model because theory suggested that standard OLS results would be subject to omitted variable bias. This paper examines the performance of a number of econometric models and selects the one that best captures highway capital's impact in a regional production function analysis. The results presented in Table 1 suggest that the spatial autoregressive model best captures the underlying spatial process present in the data. The results also indicate that, for Appalachian counties, gross output is negatively influenced by highway capital stock in neighboring counties, although the effect is small. We can interpret this result to confirm that neighbor's highway investment tends to draw productive activity away from a county, i.e., a county will experience a decrease in its production levels given an increase in neighboring county's highway capital stock.

After confirming the choice of spatial model for regional highway impact analysis, this paper provides an application of the SAR methodology in determining the direction of causality between highway capital and output. Researchers have been dwelling on this issue for four decades. Yet, they have neither reached a consensus nor found conclusive evidence to corroborate the presence of causality in either direction. The results from the two-equation SAR analysis presented in this paper (Table 3.2) suggest that, in Appalachia, causality works from highways to output, but the possibility of reverse causality can not be ruled out entirely due to multicollinearity between public capital and output.

In the past, studies on highway capital stock and its effect on output or productivity have been mostly done at the state level. One of the reasons for this may 
have been the unavailability of county level data. For the purposes of this paper, I have estimated some of the relevant variables for Appalachian counties. In the future, the same methodology could be extended to include all U.S. counties for a more comprehensive analysis. As it is, studies on regional highway effectiveness present only a partial picture since inter-regional effects are ignored.

Since Krugman (1993) found that reduction in transportation costs leads to growth only in developed regions, the new economic geography literature has emphasized the need for transportation planners to be mindful of the effect highways have on metropolitan area location patterns as well as local industries. In a world where geographic borders are becoming less and less of a constraint to information exchange and communication, it is even more important to correctly understand, capture and evaluate the economic impact of costly highway projects. This is especially true for regions like Appalachia, where accessibility has direct influence on regional economic performance. Apart from looking at the causality between highways and output, we need to examine how disparate areas respond to the same policy interventions and development stimuli. Given the wide economic gaps characterizing the region's counties, future research needs to focus on the effect of highways on distressed vs. growing counties. In my next essay I address this question. The ADHS was constructed to alleviate the geographic and economic isolation of the region. It is important to evaluate whether the results of this essay have been biased by the impact of the highway system on a handful of fast-growing metropolitan counties. 


\section{$\underline{\text { Tables }}$}

Table 3.1: Impact of Highway Capital on County Output in Appalachia: Spatial Model (Maximum Likelihood) Estimation Results Using 1992 and 1987 Data

\begin{tabular}{llll}
\hline OLS & Spatial Error Model - & $\begin{array}{c}\text { Spatial Autoregressive } \\
\text { Model }\end{array}$ \\
\hline constant & $-3.12^{* * *}$ & $-2.26^{* * *}$ & $-3.11^{* * *}$ \\
$\lambda$ & $(-29.46)$ & $(-17.25)$ & $(-30.44)$ \\
& - & $0.73^{* * *}$ & $0.07^{* * *}$ \\
Labor & $0.87^{* * *}$ & $(17.29)$ & $(4.67)$ \\
& $(39.66)$ & $0.69^{* * *}$ & $0.83^{* * *}$ \\
Private Capital & $-0.02^{* * *}$ & -0.01 & $(36.37)$ \\
& $(-4.17)$ & $(-1.62)$ & $-0.02^{* * *}$ \\
Public Capital 1987 & $0.19^{* * *}$ & $0.33^{* * *}$ & $(-3.97)$ \\
& $(8.97)$ & $(12.62)$ & $0.20^{* * *}$ \\
Own Highway & $0.02^{* *}$ & $0.02^{* *}$ & $(9.78)$ \\
Capital 1987 & $(2.19)$ & $(2.35)$ & $0.03^{* * *}$ \\
Neighbors' Highway & 0.01 & 0.002 & $(3.75)$ \\
Capital 1987 & $(1.26)$ & $(0.18)$ & $-0.02^{* *}$ \\
& & & $(-2.06)$ \\
$\mathrm{R}^{2}$ & 0.98 & 0.97 & 0.94 \\
\hline
\end{tabular}

(t-statistics and asymptotic t-statistics are in parentheses.

*** indicates significance at the $1 \%$ level,

** indicates significance at the $5 \%$ level, and

* indicates significance at the $10 \%$ level.) 
Table 3.2: Examining the Direction of Causation between Highway Capital and County Output: An Application of SAR (MLE) Analysis

\begin{tabular}{|l|c|l|c|}
\hline \multicolumn{2}{|c|}{ County Output 1987} & \multicolumn{2}{c|}{ Highway Capital 1987 } \\
\hline Variable & Coefficient & Variable & Coefficient \\
\hline constant & $-2.97^{* * *}$ & constant & $-0.57^{*}$ \\
& $(-20.18)$ & & $(-1.90)$ \\
\hline$\lambda$ & $0.13^{* * *}$ & $\lambda$ & $0.10^{*}$ \\
& $(6.52)$ & & $(1.84)$ \\
\hline Labor & $0.69^{* * *}$ & Population Growth & -0.01 \\
& $(22.86)$ & Rate 1977-1982 & $(-0.39)$ \\
\hline Private Capital & $-0.015^{* *}$ & Land Area in Sq. & 0.04 \\
& $(-2.54)$ & Miles 1980 & $(0.69)$ \\
\hline Public Capital 1982 & $0.31^{* * *}$ & Public Capital 1982 & $0.10^{* *}$ \\
& $(11.60)$ & & $(1.96)$ \\
\hline- & - & Output 1982 & 0.08 \\
& & & $(1.17)$ \\
\hline- & - & Output Growth Rate & 0.002 \\
& & $1977-1982$ & $(0.23)$ \\
\hline Own Highway & $0.03^{* * *}$ & Own Highway & $0.77^{* * *}$ \\
Capital 1982 & $(2.65)$ & Capital 1982 & $(28.21)$ \\
\hline Neighbors' Highway & $-0.03^{*}$ & Neighbors' Highway & -0.008 \\
Capital 1982 & $(-1.88)$ & Capital 1982 & $(-0.16)$ \\
\hline $\mathrm{R}^{2}$ & 0.93 & $\mathrm{R}^{2}$ & 0.89 \\
\hline
\end{tabular}

(Asymptotic t-statistics are in parentheses. *** indicates significance at the $1 \%$ level, ** indicates significance at the $5 \%$ level, and, * indicates significance at the $10 \%$ level.) 
Table 3.3: Determining the Effect of Highway Capital on Total Public Capital

\begin{tabular}{|l|l|}
\hline \multicolumn{2}{|c|}{ Total Public Capital 1987 } \\
\hline & \multicolumn{1}{|c|}{ Coefficient } \\
\hline Variable & 0.11 \\
& $(1.46)$ \\
\hline$\lambda$ & $0.08^{* * *}$ \\
& $(4.12)$ \\
\hline Population Growth Rate 1977-1982 & $0.09^{* * *}$ \\
& $(14.85)$ \\
\hline Land Area in Sq. Miles 1980 & 0.01 \\
& $(0.49)$ \\
\hline Public Capital 1982 & $0.8^{* * *}$ \\
& $(41.57)$ \\
\hline Output 1982 & $0.14^{* * *}$ \\
& $(6.65)$ \\
\hline Output Growth Rate 1977-1982 & $-0.02^{* * *}$ \\
& $(-7.70)$ \\
\hline Own Highway Capital 1982 & $-0.0^{* *}$ \\
& $(-2.49)$ \\
\hline Neighbors' Output 1982 & $-0.07^{* * *}$ \\
& $(-4.02)$ \\
\hline $\mathrm{R}^{2}$ & 0.98 \\
\hline
\end{tabular}

(Asymptotic t-statistics are in parentheses.

*** indicates significance at the $1 \%$ level,

** indicates significance at the $5 \%$ level, and,

* indicates significance at the $10 \%$ level.) 


\section{$\underline{\text { References }}$}

Anderson, A. E., Anderstig, C., and Harsman, B. (1990) 'Knowledge and communications infrastructure and regional economic change,' Regional Science and Urban Economics, vol. 20, pp. 359-76.

Anselin, L. (1988) Spatial Econometrics: Methods and Models, Kluwer Academic Publishers, The Netherlands.

. (2002) 'Under the hood: Issues in the specification and interpretation of spatial regression models,' Agricultural Economics, vol. 17, no. 3, pp. 247-267. . (2003) 'Spatial externalities, spatial multipliers and spatial econometrics', International Regional Science Review, vol. 26, no. 2, pp. 153-166(14).

Anselin, L. and Bera, A. (1998) 'Spatial dependence in linear regression models with an introduction to spatial econometrics', In A. Ullah and D. Giles (eds), Handbook of Applied Economic Statistics, Marcel Dekker, New York, pp. 237 - 289.

Anselin, L., Varga, A. and Acs, Z. (2000) 'Geographic spillovers and university research: a spatial econometric approach,' Growth and Change vol. 31, no.4, pp., 501-15.

Aschauer, A. D. (1989) 'Is public expenditure productive?,' Journal of Monetary Economics, vol. 23, no.2, pp., 177-200. . (1990) 'Is government spending stimulative?’ Contemporary Policy Issues, vol.

8, pp. 30-46.

Belsey, D.A., Kuh, E, and Welsch, R.E. (1980) Regression Diagnostics, New York: John Wiley. 
Benirschka, M. and Binkley, J.K. (1994) 'Land Price Volatility in a Geographically Dispersed Market,' American Journal of Agricultural Economics, vol. 76, no. 2, pp. 185195.

Bivand, R. (1984) 'Regression modeling with spatial dependence: an application of some class selection and estimation methods,' Geographical Analysis, vol. 16, pp. 25-37.

Blum, U. (1982) 'Effects of transportation investments on regional growth: A theoretical and empirical investigation,' Papers of the Regional Science Association, vol. 49, pp. 169-84.

Boarnet, M.G. (1998) 'Spillovers and the locational effects of public infrastructure,' Journal of Regional Science, vol. 38, pp. 381-400.

Briggs, R. (1980) 'The impact of interstate highway system on non-metropolitan growth,' U.S. Department of Transportation, Office of University Research, Washington D.C.

Burridge, P. (1981) 'Testing for a common factor in a spatial autoregressive model,' Environment and Planning A, vol. 13, pp. 795-800.

Chernoff, M. (1978) 'Density as a determinant of highway impacts,' Transportation Research Record, 686, pp. 4-9.

Costa, J. D., Elson, R.W., and Martin, R.C. (1987) 'Public capital, regional output and development: some empirical evidence,' Journal of Regional Science, vol. 27, pp. 419437.

Deno, K.T. (1988) 'The effect of public capital on U.S. manufacturing activity: 19701978,' Southern Economic Journal, vol. 2.

Garcia-Mila, T. and McGuire, T. J. (1992) 'The contribution of publicly provided inputs to states' economies', Regional Science and Urban Economics vol. 22, no.2, pp., 229 - 42. 
Harmatuck, D.J. (1996) 'The influence of transportation infrastructure on economic development,' Logistics and Transportation Review, vol. 32, pp., 63-76.

Haughwout, F.A. (1996) 'Infrastructure wages and land prices', unpublished paper, Woodrow Wilson School, Princeton University.

Holtz-Eakin, D. and Schwartz, A.E. (1995) 'Spatial productivity spillovers from Public infrastructure: Evidence from state highways,' International Tax and Public Finance vol.2, no.3, pp. 459-68.

Humphrey, C.R. and Sell, R.R. (1975) 'The impact of controlled access highways on population growth in Pennsylvania nonmetropolitan communities, 1940-1970,' Rural Sociology, vol. 42, pp. 332-43.

Isserman, A. M. (1994) 'State economic development policy and practice in the United States: A survey article,' International Regional Science Review, vol.16, issue. 1\&2, pp. 49-100.

Isserman, A. M., Rephann, T.J. and Sorenson, D.J. (1989) 'Highways and rural development: Results from quasi-experimental approaches,' West Virginia University, Regional Research Institute Working Paper 8907.

Kelejian, H.H. and Robinson, D.P. (1997) 'Infrastructure productivity estimation and its underlying econometric specifications: A sensitivity analysis,' Papers in Regional Science, vol. 76, pp., 115-31.

Krugman, P. (1991) 'Cities in space: Three simple models,' NBER Working Papers 3607, National Bureau of Economic Research, Inc. . (1993) 'Inequality and the Political Economy of Eurosclerosis,' CEPR Discussion Papers 867, C.E.P.R. Discussion Papers. 
Krugman, P. and Venables, A. J. (1995) 'The seamless world: A spatial model of international specialization,' CEPR Discussion Papers 1230, C.E.P.R. Discussion Papers. Lichter, D.T. and Fuguitt, G.V. (1980) 'Demographic response to transportation innovation: the case of the interstate highway,' Social Forces, vol. 59, pp. 492-511.

Lynde, C. and Richmond, J. (1992), ‘The role of public capital in production,' Review of Economics and Statistics, vol. 74, pp. 37-44.

Martin, P. (1998) 'Can regional policies affect growth and geography in Europe?,' World Economy, vol. 21, no. 6, pp. 757-774.

Mera, K. (1975) 'Income Distribution and Regional Development,' Tokyo. University of Tokyo Press.

Mikelbank, B.A. and Jackson, R.W. (2000) 'The role of space in public capital research,' International Regional Science Review, vol. 23, no. 3, pp., 235-58.

Moomaw, R.L, Mullen, J.K. and Williams, M (1995) 'The interregional impact of infrastructure capital,' Southern Economic Journal, vol. 61, pp., 830-45.

Munnell, A.H. (1990a) 'How does public infrastructure affect regional economic performance', New England Economic Review, September-October: 11 - 32.

. (1990b) 'Why has productivity growth declined? Productivity and public investment,' New England Economic Review, January-February, pp. 3-22. . (1992) 'Policy watch: Infrastructure investment and economic growth,' The Journal of Economic Perspectives, vol. 6, no. 4.

Nijkamp, P. (1986), 'Infrastructure and regional development: A multidimensional policy analysis,' Empirical Economics, vol. 11, pp. 1 -21. 
Ord, J.K. (1975) 'Estimation methods for models of spatial interaction', Journal of the American Standard Association, Vol. 70, pp. 120 -6.

Puga, D. (2002) 'European regional policy in light of recent location theories,' Journal of Economic Geography, vol. 2, issue. 4, pp. 372-406.

Venables, A. and Gasiorek, M. (1999) 'Evaluating regional infrastructure: a computable general equilibrium approach,' in Study of the Socio-economic Impact of the Projects Funded by the Cohesion Fund - A Modelling Approach, vol. 2. Office for Official publications of the European communities, Luxembourg.

Yilmaz, S., Haynes, K.E., and Dinc, M. (2002) 'Geographic and network neighbors: Spillover effects of telecommunications infrastructure,' Journal of Regional Science, vol. 42, no.2, pp. 339-60. 


\section{Chapter 4}

An Examination of the Differential Impact of Highway Capital Investment on Economically Disparate Appalachian Counties 


\title{
An Examination of the Differential Impact of Highway Capital Investment on Economically Disparate Appalachian Counties
}

\author{
Samia Islam \\ Department of Economics \\ West Virginia University \\ Morgantown, WV 26506 \\ Phone: (304) 293-2166 \\ Email: saislam@mail.wvu.edu.
}

\begin{abstract}
The economic performance of Appalachian counties varies substantially across the region. The Appalachian Regional Commission (ARC) has divided the 411 regional counties into four major categories: distressed, transitional, competitive and attainment. This paper applies spatial models that account for spatial interdependence to evaluate the impact of Appalachian highways on economically disparate counties. Using a spatial autoregressive model in a production function framework, I find that distressed counties gain from highways whereas competitive counties actually suffer from a negative backwash effect that tends to draw productive activity away from these counties into neighboring counties. Competitive counties are also not affected by spatial spillovers.
\end{abstract}

JEL Classification: R11, R42, C11, C49

Keywords: Highway Capital, Appalachia, Economically Disparate Counties 


\subsection{Introduction}

Other than the presence of hilly terrain, Appalachian counties are not homogenous in any respect. The counties vary not only in terms of size and population but also their level of economic attainment. While a small number of the 411 counties have performed well over the last four decades, a majority of the region's counties have failed to perform up to par. Regional policy makers have taken many initiatives to provide economic stimuli to these backward areas. Some measures have worked better than others. The most costly intervention has undoubtedly been the Appalachian Development Highway System (ADHS).

The response of declining regions to a stimulus such as a new highway may be different from the response of prosperous regions. Likewise, a highly developed urban center may respond differently than a less developed rural area. For policy purposes, this paper investigates whether accessibility fosters faster or higher development in some counties compared with others.

Regional development policies are usually geared to attract more industry and commerce, and consequently to spur economic activity. Research findings that more clearly demonstrate the differential impact of highways on output or productivity in economically disparate counties in Appalachia can assist in framing informed regional development policy. The results from this paper support and corroborate other authors' results that distressed, non-metropolitan counties gain from major highway investments (Bickford 1986, Deno 1988, Kilkenny 1998). Researchers, however, have not reached a consensus on the impact of highways on rural vs. urban, growing vs. depressed or core vs. periphery areas. 
Research on differential impact of transportation on disparate regions goes back a long way. According to Mikelbank and Jackson (2000), Hirschman considered the effects of transport investment between 'growth poles' and the 'hinterland' in his 1958 paper. Later, many studies looked at areas with different characteristics, but their findings were not conclusive (Hansen 1965; Eberts 1986; Costa, Elson, and Martin 1987; Moomaw, Mullen, and Williams 1995; Mikelbank and Jackson 1999).

Studies focusing on total population and total employment have generally found positive highway effects (Botham 1980; Dodgson 1974; Gaegler et al. 1979; Carlino and Mills 1987; Isserman et al. 1989) but this relationship is much weaker for nonmetropolitan or rural areas (Hansen 1973; Humphrey et al. 1977; Miller 1979; Briggs 1980; Harris 1980; Hilewick et al. 1980). Indeed, these latter studies find that the distance from a metropolitan area is a greater determinant of nonmetropolitan growth than the presence of highways.

Urbanized and dynamic areas, however, are often disproportionately favored for new highways (Humphrey and Sell 1975; Briggs 1980; Lichter and Fuguitt 1980). Urban areas have existing favorable conditions that make them more likely to grow faster than rural regions. A failure to control for these circumstances and isolate the effects of the prior conditions from the highway effects can cause an upward bias to estimates of highway effect.

Studies that have looked at different geographical regions found that the southern and mountain states gain the most from new highways (Briggs 1980; Munnell 1990). Highway socio-economic effects are found to be greater in urbanized and metropolitan areas with higher population density (Chernoff 1978; Isserman et al. 1989). On the other 
hand, Bickford et al (1986) and Deno (1988) find the largest employment effects for federal grants in regions that previously experienced low growth as well as distressed areas. While studying agglomerations, Kilkenny (1998) finds an initially negative, but ultimately positive, relationship between reductions in transport costs and rural development using a two-region general equilibrium model.

Generally, highways have been found to have greater impact on less industrialized regions. Urbanization level and metro proximity are important determinants, and declining regions respond less than slow growing regions.

This paper proceeds as follows: In Section II, I discuss the methodology used and provide a description of the data. Section III presents the results. Section IV contains the concluding remarks. All tables are reported in a separate section at the end of this chapter. For comparison, standard OLS results from the three model specifications are also included. ARC category for all 411 counties in the region is reported in the Appendix.

\subsection{Methodology and Data}

I use a structural macro model to test the impact of public investment in highways on output. I follow Boarnet's (1998) standard production function approach, treating each county as a single entity whose output depends on public capital, highway capital, private capital and labor. The production function for a county is shown below:

$$
Q=f(L, K, G, H W Y, S H W Y)
$$

where $Q=$ county output; $L=$ labor in county; $K=$ private capital stock in county; $G=$ public capital stock in county, excluding highways; $H W Y$ = highway capital in county; and $S H W Y=$ highway capital in all other counties in region. 
In the case of public highways, a substantially strong spatial process should be observed over geographical space. To give structure to the neighborhood we define a spillover variable, $\boldsymbol{S H W Y}$. I use the nearest-neighbor criterion to define a neighborhood structure for each county, which would include all counties that share a common geographical border. This specification is in keeping with the spillover variable constructed by Yilmaz, Haynes and Dinc (2002) for their study on telecommunication networks. The spillover variable is calculated as:

$$
\boldsymbol{S H W Y}=W H W Y_{j}=\text { all (geographic) neighbors, }
$$

where each element of $W, \mathrm{w}_{i, j}=1 \quad$ if counties $\mathrm{i}$ and $\mathrm{j}$ share a common border, and

$$
=0 \text { otherwise. }
$$

Formally, the model specification is as follows:

$$
\log (Q)=\alpha_{o}+\alpha_{1} \log (L)+\alpha_{2} \log (K)+\alpha_{3} \log \left(G_{-1}\right)+\alpha_{4} \log \left(H W Y_{-1}\right)+\alpha_{5} \log \left(\sum W H W Y_{-1}\right)+\varepsilon_{s t}
$$

where the subscript, ${ }_{-1}$, indicates a one-period (five year) lag.

I adjust the specification of the model to illustrate the effects of highways on the four types of counties in the regions. Since only 9 counties have reached 'attainment' and 22 are designated as 'competitive', I lump these two ARC categories together and refer to the 31 counties as 'competitive'. The other two categories ('distressed' and 'transitional') remain unaltered. ${ }^{24}$

\footnotetext{
${ }^{24}$ The model specification allows separate spatial weights for each of the three categories. This is less restrictive than constraining all categories to have the same weights matrix. If constraining the spatial weights matrix to be identical for the three categories is valid, then the procedure used in this essay is inefficient. If, however, the constraint was imposed, but was invalid, then the results from that analysis would be biased and inconsistent, which is a more serious error.
} 
County output data are derived by apportioning gross state product to counties based on total county personal income. ${ }^{25}$ Gross state product data are available from the U.S. Bureau of Economic Analysis (BEA). Labor force data are from the U.S. Bureau of Labor Statistics (BLS) as published in the 1998 USA Counties data CD released by the U.S. Bureau of the Census.

Public capital stock data are not available by county. We can estimate it by apportioning the state totals to counties. State level public capital data come from Munnell (1990), as well as the apportioning method, which also follows Costa, Elson and Martin (1987). To estimate county public capital, I used the ratio of county total direct government expenditure (obtained from Census of Governments) to the state total for each year and apportioned the total state public capital stock to corresponding counties. Yilmaz, Haynes and Dinc (2002) have found that government direct capital expenditures for all states and the United States follow the same trend. This confirms that each county's share in state capital expenditure is a good proxy for the size of its public capital.

Estimating private capital stock for each year by county is more problematic. Manufacturing sector value-added and wage and salary compensation data are available at the state and county level from the U.S. Bureau of the Census. ${ }^{26}$ Using these data, I estimated county private capital stock $\left(K_{i}\right)$ with the following procedure (Yilmaz, Haynes and Dinc 2002):

$$
K_{i}=\left[\left(V A D D_{i}-W S_{i}\right) /\left(V A D D_{n}-W S_{n}\right)\right] K_{n}
$$

\footnotetext{
${ }^{25}$ This is the methodology used by the Southern California Association of Governments to estimate county product within their region.

${ }^{26}$ USA Counties Data CD.
} 
where $i$ indexes counties and $n$ indexes the state. $V A D D$ is total value added (output) and WS is wage and salary expenditures for private manufacturing industries. So, VADD -WS represents returns to private capital indicating the size of the private capital stock in each county. ${ }^{27}$

State and local highway capital expenditure data come from the Federal Highway Administration (FHWA) and the federal highway capital expenditure data by county are from the Census of Governments. Public capital investments in the current period are not expected to affect current output. Therefore, five-year lagged public, private and highway capital stock data are used in the model in order to allot a reasonable time for the effects of these investments to be reflected in current output. Output, labor, and private capital data are available for the years 1977, 1982, 1987 and 1992. Highway and public capital stock data are available for 1972, 1977, 1982 and $1987 .^{28}$

\subsection{Results}

For the 121 Appalachian counties that are designated as 'distressed,' labor and public capital are highly significant and positive, with labor having the strongest influence (Table 4.1). ${ }^{29}$ Own highway capital is also positive, and significant at the $5 \%$ level implying that an increase in own highway capital investment will bring about a small but positive change in output. Neighbors' highway capital is positive but we cannot reject the null hypothesis of a zero coefficient. This leads us to conclude that neighbors' highway capital does not have much of an influence for distressed counties. Rather, labor

\footnotetext{
${ }^{27}$ Private capital stock here only includes data for private manufacturing industries. This measure overlooks private capital in other industries, such as mining, construction, etc. The primary reason for omitting the other sectors from our analysis was data unavailability.
} 
and public capital are the major determinants for increases in output or productive activity.

At first glance, the negative sign of the private capital coefficient may cause concern. The private capital data used here, however, only accounts for the manufacturing capital stock in these counties. Given the nature of the private capital data we used and the regional industrial composition, therefore, the negative sign can be interpreted as an indicator of the rise of service sector activities in the region in the last two decades.

Other factors might also plausibly explain the negative sign for private capital. It could reflect crowding out of private capital due to increased public capital investments in the region. If lagged public capital crowds out current period private capital then the coefficient may be picking up these effects. Using lagged private capital as a regressor may help address this issue. Using lagged private capital instead of current period private capital as a RHS variable, however, does not mitigate the statistically significant negative sign for the coefficient of private capital.

The calculation of output, using the total personal income ratio in each county to apportion gross state product to counties, might also influence the capital stock outcome, especially its statistical significance in the case of 'distressed' counties. Transfer payments, one component of total personal income, tend to be relatively higher in poorer counties, due to income assistance payments. If private capital is less likely to move to these poor counties where high levels of public assistance payments prop up incomes,

\footnotetext{
${ }^{28}$ All econometric analysis was done in MATLAB using the programs from the Spatial Econometrics toolbox, courtesy of Professor James P. LeSage, University of Toledo. Available for free download at http://www.spatial-econometrics.com.

${ }^{29}$ Since all variables used in the model are in log form, the coefficient estimates refer to elasticities.
} 
then transfer payments and total personal income could be negatively correlated. A simple correlation analysis between total personal income and transfers, however, finds evidence of positive and significant correlation. Further, total personal income and private capital stock are positively correlated for this Appalachian sample. While a complex multivariate correlation analysis would be necessary to answer this question completely, these correlations suggest that the negative sign of the private capital coefficient is not directly driven by transfer payments.

The spillover parameter, $\lambda$, measures the diffusion of output's impact through space and is significant at the $5 \%$ level. Although not very substantial in magnitude, this suggests a moderate, but definite, spatial process in the output variable. A county's economic performance is directly affected by that of its neighbors, and vice versa.

Table 4.2 presents the SAR analysis results for the 259 Appalachian counties that are designated as 'transitional.’ Once again, labor, public capital and own highway capital are the strongest positive influences on output. Private capital stock, although still negative, is no longer significantly different from zero. This can be interpreted to mean that new capital investment in private manufacturing industries does not affect output in the transitional counties as they are likely washed out by the growth in service sector activities. The spillover effect is positive and significant at the $5 \%$ level, but much smaller in magnitude compared with results for distressed counties. Neighbors' highway capital is negative and significant at the $10 \%$ level, indicating a negative backwash effect, i.e., that highway expansions in surrounding counties can draw economic activity away.

For the 31 'competitive’ counties in the region, coefficients of labor and public capital are highly significant and positive, whereas the coefficient for own highway 
capital is not (Table 4.3). Neighbors' highway capital is negative and significant at the 5\% level implying that highway capital investment draws output away from own county. Here, the presence of a negative backwash effect of neighbors' highway capital expansion actually depresses the positive own highway effects, unlike the case of the distressed counties where neighbors' highway capital does not draw output away and only the positive own highway effects matter.

The spillover process is no longer evident, prompting a check for presence of spatial autocorrelation with a Moran's $I$ test on a standard OLS model. The Moran's I statistic is smaller than 1.96 indicating that we cannot reject the null hypothesis of no spatial autocorrelation. OLS results are similar in scope to the SAR results (Table 4.4). Labor and public capital coefficients are positive and highly significant. Private capital still has a negative but statistically insignificant coefficient. Adding more highway capital does not significantly impact output in these counties that have already reached a level of economic prosperity. Neighbors' highway expansions, however, do seem to draw productive activity away from them. A Moran's I test of standard OLS regressions for the other two categories of counties reveals Moran’s I statistics greater than 1.96, prompting us to reject the null hypothesis of no spatial autocorrelation.

Using SAR in the case of distressed and transitional counties where the spatial process is evident yields lower coefficient estimates for all variables in the model indicating that the omitted variable type bias has been corrected. We also have a definite idea about the strength and direction of the transmission/diffusion of output's impact across counties, i.e., through space. 
In all three specifications of the model, Belsey, Kuh and Welsch multicollinearity diagnostics ${ }^{30}$ indicate substantial multicollinearity between labor and public capital. The effects of severe multicollinearity, however, are typically reflected in low t-statistics. Since the t-statistics for labor and public capital from all three output regressions are quite high, multicollinearity does not adversely affect conclusions from the empirical results.

\subsection{Conclusion}

Highway infrastructure improvement helps reduce the costs of procuring inputs and distributing outputs, and increases productivity through improved and increased services. It also increases labor and private capital productivity since labor markets can function better due to greater mobility and/or accessibility.

For Appalachia, highways hold a greater significance due to the isolation of the region and the ruggedness of its terrain. A mile of highway is twice as costly to build in Appalachia as in the rest of the United States. Careful study is, therefore, necessary not only to evaluate the impact of highways on the region as a whole but for a clearer understanding of how individual counties benefit given their existing economic condition. The Appalachian Regional Commission (ARC) has designated each county into one of four separate categories according to their economic performance: 'distressed,' 'transitional,' 'competitive' and 'attainment'. I use this information to test the effect of highways on different categories of counties. The results should reflect how highway capital impacts counties that are in different stages of economic development.

\footnotetext{
${ }^{30}$ Belsey, Kuh and Welsch (1980).
} 
In the existing literature, highway capital has generally been found to have only a limited effect on economic growth but most of these studies did not consider the effects of spatial autocorrelation. To address this shortcoming, I apply a spatial autoregressive model to analyze the impact of highways on economically disparate counties. Spatial models give adequate consideration to interactions of actors in space and spatial interdependence. They should, therefore, yield more conclusive and complete evidence of the effectiveness of expensive highway projects on regional economic growth. Moran's I tests indicate that, for both 'distressed' and 'transitional' counties, positive spatial spillovers are clearly evident. For the 'competitive' category (which also includes the 9 'attainment' counties), however, the spatial spillover parameter, $\lambda$, is not significantly different from zero.

I also find that for distressed counties, labor and public capital are the major determinants for increases in output or productive activity. Highway capital investments in neighboring counties do not have much of an influence. Labor, public capital and own highway capital are the strongest positive influences on output in the transitional counties. Neighbor's highway capital has a negative backwash effect of own county output. In all three categories, the coefficient for private capital stock is negative, but it is only significant for distressed counties, implying that these counties either rely on, or are continuing to invest more capital in, declining industries.

These findings have a direct relevance for regional transportation policy and are consistent with the findings of Bickford et al. (1986) and Deno (1988). Both of these authors found that the largest employment effects for federal highway grants are in regions that previously experienced low growth and in distressed areas. My results 
provide additional evidence that highway projects, however costly, do indeed help the distressed, non-metropolitan counties. This supports the ADHS' primary policy objective of bringing the isolated counties in Appalachia out of poverty and augmenting their economic viability. 
Tables

Table 4.1: Output in Distressed Counties: SAR (Maximum Likelihood Estimation) Analysis

\begin{tabular}{ll}
\hline Variable & Coefficient \\
\hline Constant & $-3.50^{* * *}$ \\
Labor & $(-13.01)$ \\
& $0.78^{* * *}$ \\
Private capital & $(18.11)$ \\
& $-0.03^{* * *}$ \\
Public capital (-1) & $(-3.66)$ \\
& $0.26^{* * *}$ \\
Own Highway capital (-1) & $(7.20)$ \\
Neighbor's Highway Capital $(-1)$ & $0.04^{* *}$ \\
& $(2.06)$ \\
Spillover Parameter, $\lambda$ & 0.03 \\
$R^{2}$ & $(0.76)$ \\
& $0.13^{* * *}$ \\
& $(3.16)$ \\
\end{tabular}

(Asymptotic t-statistics are in parentheses. *** indicates significance at the $1 \%$ level, ** indicates significance at the $5 \%$ level and * indicates significance at the 10\% level.) 
Table 4.2: Output in Transitional Counties: SAR (Maximum Likelihood Estimation) Analysis

\begin{tabular}{|c|c|}
\hline Variable & Coefficient \\
\hline Constant & $\begin{array}{l}-3.27 * * * \\
(-23.06)\end{array}$ \\
\hline Labor & $\begin{array}{l}0.92 * * * \\
(34.0)\end{array}$ \\
\hline Private capital & $\begin{array}{l}-0.01 \\
(-1.59)\end{array}$ \\
\hline Public capital (-1) & $\begin{array}{l}0.11^{* * *} \\
(4.64)\end{array}$ \\
\hline Own Highway capital (-1) & $\begin{array}{l}0.03 * * * \\
(3.13)\end{array}$ \\
\hline Neighbor's Highway Capital (-1) & $\begin{array}{l}-0.02^{*} \\
(-1.70)\end{array}$ \\
\hline Spillover Parameter, $\lambda$ & $\begin{array}{l}0.04 * * \\
(2.04)\end{array}$ \\
\hline$R^{2}$ & 0.94 \\
\hline
\end{tabular}


Table 4.3: Output in Competitive Counties: SAR (Maximum Likelihood Estimation) Analysis

\begin{tabular}{ll}
\hline Variable & Coefficient \\
\hline Constant & $-1.82^{* * *}$ \\
Labor & $(-2.80)$ \\
& $0.72^{* * *}$ \\
Private capital & $(6.59)$ \\
Public capital (-1) & -0.01 \\
Own Highway capital (-1) & $(-0.30)$ \\
Neighbor's Highway Capital (-1) & $0.30^{* * *}$ \\
Spillover Parameter, $\lambda$ & $(2.94)$ \\
$R^{2}$ & 0.002 \\
& $(0.06)$ \\
& $-0.08^{* *}$ \\
& $(-2.10)$ \\
& 0.004 \\
& $(0.07)$ \\
\hline
\end{tabular}

(Asymptotic t-statistics are in parentheses. $* * *$ indicates significance at the $1 \%$ level, ** indicates significance at the $5 \%$ level and * indicates significance at the $10 \%$ level.) 
Table 4.4: Output in Competitive Counties: OLS Results

\begin{tabular}{ll}
\hline Variable & Coefficient \\
\hline Constant & $-1.79 * * *$ \\
& $(-2.95)$ \\
Labor & $0.72^{* * *}$ \\
& $(5.95)$ \\
Private capital & -0.0047 \\
& $(-0.28)$ \\
Public capital (-1) & $0.30^{* * *}$ \\
& $(2.78)$ \\
Own Highway capital (-1) & 0.001 \\
Neighbor's Highway Capital (-1) & $(0.03)$ \\
& $-0.08^{* *}$ \\
$R^{2}$ & $(-2.17)$ \\
\hline (t-statistics are in parentheses. $* * *$ & 0.97 \\
indicates significance at the 5\% level and * indicates significance at the 10\% level.) & \\
& \\
Moran's I-test for spatial correlation in residuals \\
Moran's I-statistic & 0.65612072 \\
Marginal Probability & 0.32168395 \\
Mean & -0.05947194 \\
Standard deviation & 0.10066185
\end{tabular}


Table 4.5: Output in Distressed Counties: OLS results

\begin{tabular}{ll}
\hline \multicolumn{1}{c}{ Variable } & Coefficient \\
\hline Constant & $-3.08^{* * *}$ \\
& $(-12.79)$ \\
Labor & $0.77^{* * *}$ \\
& $(16.85)$ \\
Private capital & $-0.03^{* * *}$ \\
Public capital (-1) & $(-3.63)$ \\
& $0.30^{* * *}$ \\
Own Highway capital (-1) & $(8.32)$ \\
& 0.02 \\
Neighbors' Highway capital (-1) & $(1.31)$ \\
& $0.09^{* * *}$ \\
$R^{2}$ & $(3.07)$ \\
(t-statistics are in parentheses. ${ }^{* * *}$ indicates significance at the 1\% level, ** & 0.96 \\
indicates significance at the 5\% level and * indicates significance at the 10\% level.) & \\
& \\
Moran's I-test for spatial correlation in residuals \\
Moran's I-statistic & 6.38849555 \\
Marginal Probability & 0.00000000 \\
Mean & -0.02201789 \\
Standard deviation & 0.05121300
\end{tabular}


Table 4.6: Output in Transitional Counties: OLS Results

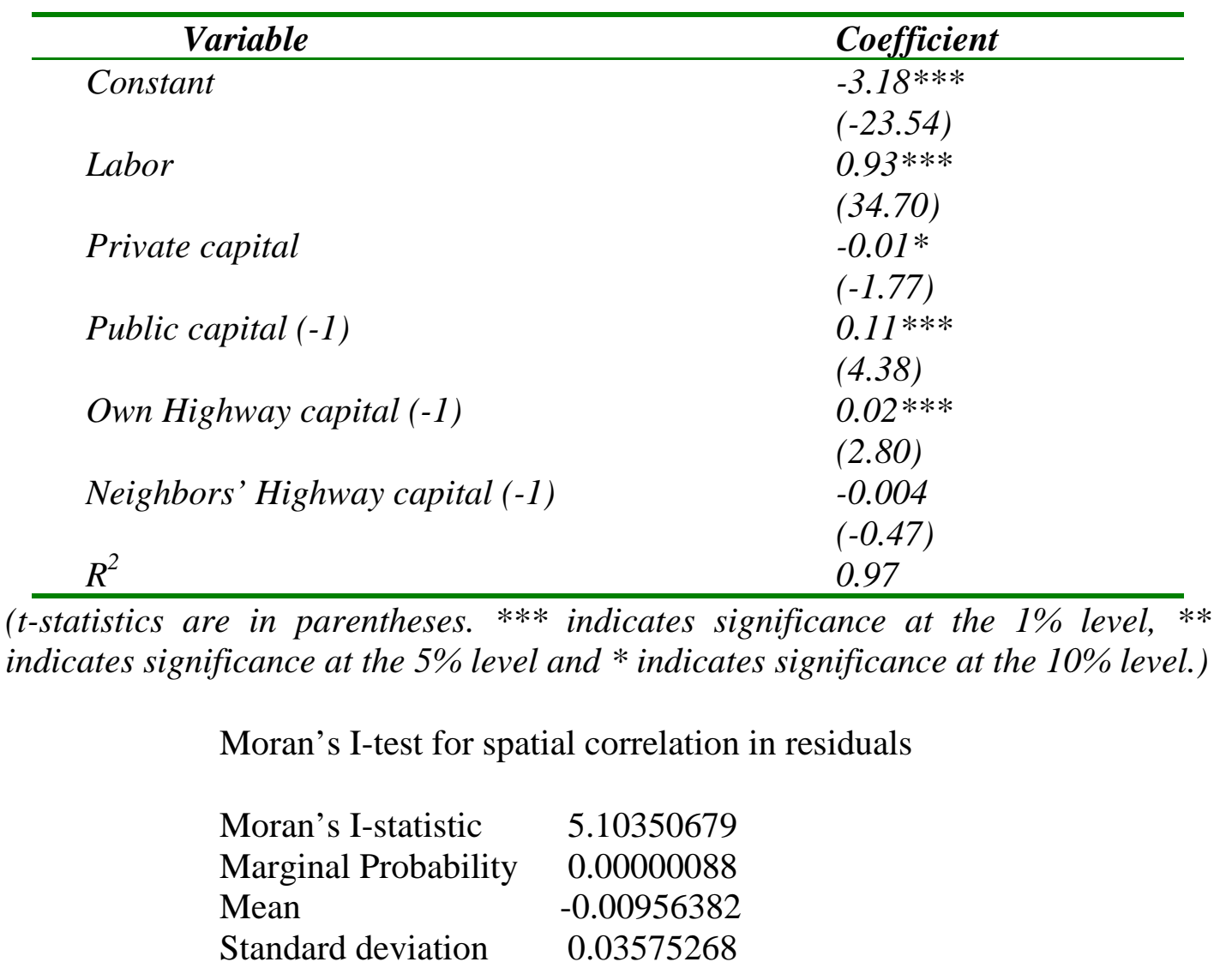




\section{Appendix}

Table A-1: Counties Designated as 'Attainment and Competitive' by the Appalachian Regional Commission (ARC), 2000

$\begin{array}{ll}\text { County } & \text { ARC Category } \\ \text { Shelby, AL } & \text { Attainment } \\ \text { Forsyth, GA } & \text { Attainment } \\ \text { Davie, NC } & \text { Attainment } \\ \text { Forsyth, NC } & \text { Attainment } \\ \text { Polk, NC } & \text { Attainment } \\ \text { Allegheny, PA } & \text { Attainment } \\ \text { Greenville, SC } & \text { Attainment } \\ \text { Hamilton, TN } & \text { Attainment } \\ \text { Madison, AL } & \text { Competitive } \\ \text { Morgan, AL } & \text { Competitive } \\ \text { Bartow, GA } & \text { Competitive } \\ \text { Cherokee, GA } & \text { Competitive } \\ \text { Dawson, GA } & \text { Competitive } \\ \text { Douglas, GA } & \text { Competitive } \\ \text { Habersham, GA } & \text { Competitive } \\ \text { Hall, GA } & \text { Competitive } \\ \text { Pickens, GA } & \text { Competitive } \\ \text { Whitfield, GA } & \text { Competitive } \\ \text { Washington, MD } & \text { Competitive } \\ \text { Broome, NY } & \text { Competitive } \\ \text { Buncombe, NC } & \text { Competitive } \\ \text { Caldwell, NC } & \text { Competitive } \\ \text { Henderson, NC } & \text { Competitive } \\ \text { Clermont, OH } & \text { Competitive } \\ \text { Butler, PA } & \text { Competitive } \\ \text { Montour, PA } & \text { Competitive } \\ \text { Oconee, SC } & \text { Competitive } \\ \text { Botetourt, VA } & \text { Competitive } \\ \text { Jefferson, WV } & \text { Competitive }\end{array}$


Table A-2: Counties Designated as ‘Transitional’ by ARC, 2000

\author{
County \\ Blount, AL \\ Calhoun, AL \\ Chambers, AL \\ Cherokee, AL \\ Chilton, AL \\ Clay, AL \\ Cleburne \\ Colbert, AL \\ Coosa, AL \\ Cullman, AL \\ De Kalb, AL \\ Elmore, AL \\ Etowah, AL \\ Jackson, AL \\ Jefferson, AL \\ Lamar, AL \\ Lauderdale, AL \\ Lawrence, AL \\ Limestone, AL \\ Marion, AL \\ Marshall, AL \\ Randolph, AL \\ St. Clair, AL \\ Talladega, AL \\ Tallapoosa, AL \\ Tuscaloosa, AL \\ Walker, AL \\ Banks, GA \\ Barrow, GA \\ Carroll, GA \\ Catoosa, GA \\ Chattooga, GA \\ Dade, GA \\ Elbert, GA \\ Fannin, GA \\ Floyd, GA \\ Franklin, GA \\ Gilmer, GA \\ Gordon, GA \\ Haralson, GA \\ Hart, GA \\ Jackson, GA \\ Lumpkin, GA \\ Madison, GA \\ Murray, GA \\ Paulding, GA \\ Polk, GA
}

\section{County}

Rabun, GA

Stephens, GA

Towns, GA

Union, GA

Walker, GA

White, GA

Boyd, KY

Clark, KY

Fleming, KY

Garrard, KY

Greenup, KY

Laurel, KY

Madison, KY

Montgomery, KY

Pulaski, KY

Allegany, MD

Garrett, MD

Alcorn, MS

Calhoun, MS

Itawamba, MS

Lee, MS

Lowndes, MS

Pontotoc, MS

Prentiss, MS

Tippah, MS

Union, MS

Webster, MS

Allegany, NY

Cattaraugus, NY

Chautauqua, NY

Chemung, NY

Chenango, NY

Cortland, NY

Delaware, NY

Otsego, NY

Schoharie, NY

Schuyler, NY

Steuben, NY

Tioga, NY

Tompkins, NY

Alexander, NC

Alleghany, NC

Ashe, NC

Avery, NC

Burke, NC

Clay, NC

Haywood, NC
County

Jackson, NC

McDowell, NC

Macon, NC

Madison, NC

Mitchell, NC

Rutherford, NC

Stokes, NC

Surry, NC

Transylvania, NC

Watauga, NC

Wilkes, NC

Yadkin, NC

Yancey, NC

Belmont, $\mathrm{OH}$

Brown, $\mathrm{OH}$

Carroll, $\mathrm{OH}$

Columbiana, $\mathrm{OH}$

Coshocton, $\mathrm{OH}$

Guernsey, $\mathrm{OH}$

Harrison, $\mathrm{OH}$

Highland, $\mathrm{OH}$

Hocking, $\mathrm{OH}$

Holmes, $\mathrm{OH}$

Jefferson, $\mathrm{OH}$

Muskingum, $\mathrm{OH}$

Noble, $\mathrm{OH}$

Perry, $\mathrm{OH}$

Ross, $\mathrm{OH}$

Tuscarawas, $\mathrm{OH}$

Washington, $\mathrm{OH}$

Armstrong, PA

Beaver, PA

Bedford, PA

Blair, PA

Bradford, PA

Cambria, PA

Cameron, PA

Carbon, PA

Centre, PA

Clarion, PA

Clearfield, PA

Clinton, PA

Columbia, PA

Crawford, PA

Elk, PA

Erie, PA

Forest, PA 
Table A-2: Counties designated as 'Transitional' by the ARC, 2000 (continued)

County
Fulton, PA
Huntingdon, PA
Indiana, PA
Jefferson, PA
Juniata, PA
Lackawanna, PA
Lawrence, PA
Luzerne, PA
Lycoming, PA
McKean, PA
Mercer, PA
Mifflin, PA
Monroe, PA
Northumberland, PA
Perry, PA
Pike, PA
Potter, PA
Schuylkill, PA
Snyder, PA
Somerset, PA
Sullivan, PA
Susquehanna, PA
Tioga, PA
Union, PA
Venango, PA
Warren, PA
Washington, PA
Wayne, PA
Westmoreland, PA
Wyoming, PA
Anderson, SC
Cherokee, SC
Pickens, SC
Spartanburg, SC
Anderson, TN
Bedford, TN
Blount, TN
Bradley, TN
Cannon, TN
Carter, TN
Claiborne, TN
Coffee, TN
Cumberland, TN
DeKalb, TN
Franklin, TN
Grainger, TN

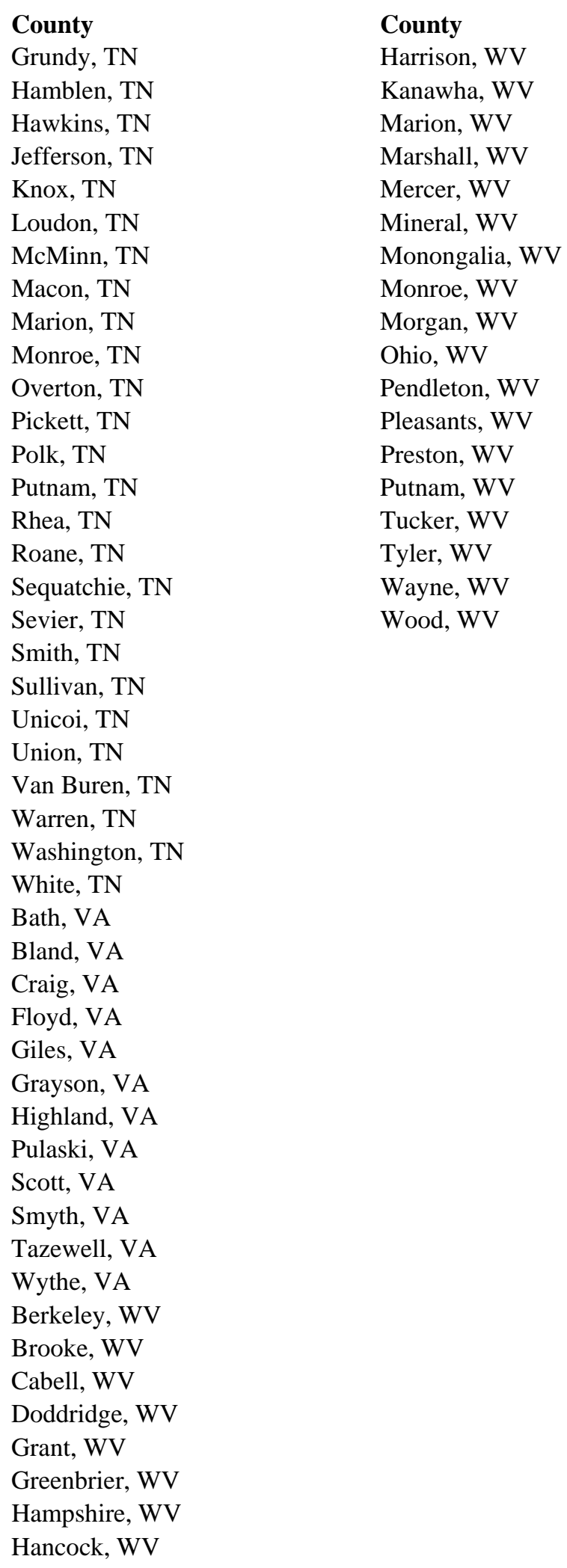

\section{County}

Grundy, TN

Hamblen, TN

Hawkins, TN

Jefferson, TN

Knox, TN

Loudon, TN

McMinn, TN

Macon, TN

Marion, TN

Monroe, TN

Overton, TN

Pickett, TN

Polk, TN

Putnam, TN

Rhea, TN

Roane, TN

Sequatchie, TN

Sevier, TN

Smith, TN

Sullivan, TN

Unicoi, TN

Union, TN

Van Buren, TN

Warren, TN

Washington, TN

White, TN

Bath, VA

Bland, VA

Craig, VA

Floyd, VA

Giles, VA

Grayson, VA

Highland, VA

Pulaski, VA

Scott, VA

Smyth, VA

Tazewell, VA

Wythe, VA

Berkeley, WV

Brooke, WV

Cabell, WV

Doddridge, WV

Grant, WV

Greenbrier, WV

Hampshire, WV

Hancock, WV

\section{County}

Harrison, WV

Kanawha, WV

Marion, WV

Marshall, WV

Mercer, WV

Mineral, WV

Monongalia, WV

Monroe, WV

Morgan, WV

Ohio, WV

Pendleton, WV

Pleasants, WV

Preston, WV

Putnam, WV

Tucker, WV

Tyler, WV

Wayne, WV

Wood, WV 
Table A-3: Counties Designated as 'Distressed' by the ARC, 2000

County
Bibb, AL
Fayette, AL
Franklin, AL
Hale, AL
Macon, AL
Pickens, AL
Winston, AL
Adair, KY
Bath, KY
Bell, KY
Breathitt, KY
Carter, KY
Casey, KY
Clay, KY
Clinton, KY
Cumberland, KY
Edmonson, KY
Elliott, KY
Estill, KY
Floyd, KY
Green, KY
Harlan, KY
Hart, KY
Jackson, KY
Johnson, KY
Knott, KY
Knox, KY
Lawrence, KY
Lee, KY
Leslie, KY
Letcher, KY
Lewis, KY
Lincoln, KY
McCreary, KY
Magoffin, KY
Martin, KY
Menifee, KY
Monroe, KY
Morgan, KY
Owsley, KY
Perry, KY
Pike, KY
Powell, KY
Rockcastle, KY

\author{
County \\ Rowan, KY \\ Russell, KY \\ Wayne, KY \\ Whitley, KY \\ Wolfe, KY \\ Benton, MS \\ Chickasaw, MS \\ Choctaw, MS \\ Clay, MS \\ Kemper, MS \\ Marshall, MS \\ Monroe, MS \\ Montgomery, MS \\ Noxubee, MS \\ Oktibbeha, MS \\ Panola, MS \\ Tishomingo, MS \\ Winston, MS \\ Yalobusha, MS \\ Cherokee, NC \\ Graham, NC \\ Swain, NC \\ Adams, $\mathrm{OH}$ \\ Athens, $\mathrm{OH}$ \\ Gallia, $\mathrm{OH}$ \\ Jackson, $\mathrm{OH}$ \\ Lawrence, $\mathrm{OH}$ \\ Meigs, $\mathrm{OH}$ \\ Monroe, $\mathrm{OH}$ \\ Morgan, $\mathrm{OH}$ \\ Pike, $\mathrm{OH}$ \\ Scioto, $\mathrm{OH}$ \\ Vinton, $\mathrm{OH}$ \\ Fayette, PA \\ Greene, PA \\ Campbell, TN \\ Clay, TN \\ Cocke, TN \\ Fentress, TN \\ Hancock, TN \\ Jackson, TN \\ Johnson, TN \\ Meigs, TN \\ Morgan, TN
}

County

Scott, TN

Buchanan, VA

Dickenson, VA

Lee, VA

Russell, VA

Wise + Norton, VA

Barbour, WV

Boone, WV

Braxton, WV

Calhoun, WV

Clay, WV

Fayette, WV

Gilmer, WV

Jackson, WV

Lewis, WV

Lincoln, WV

Logan, WV

McDowell, WV

Mason, WV

Mingo, WV

Nicholas, WV

Pocahontas, WV

Raleigh, WV

Randolph, WV

Ritchie, WV

Roane, WV

Summers, WV

Taylor, WV

Upshur, WV

Webster, WV

Wetzel, WV

Wirt, WV

Wyoming, WV 


\section{References}

Belsey, D.A., Kuh, E, and Welsch, R.E. (1980) Regression Diagnostics, New York: John Wiley.

Bickford, D.J., Clapp, J.M. and Vehorn, C.L. (1986) Effects of federal economic development programs, Growth and Change, vol. 17. pp. 1 - 16.

Boarnet, M.G. (1998) 'Spillovers and the locational effects of public infrastructure,' Journal of Regional Science, vol. 38, pp. 381-400.

Botham, R.W. (1970) 'The regional development effects of road investment,' Transportation Planning and Technology, vol. 6. pp. 97-108.

Briggs, R. (1980) 'The impact of interstate highway system on non-metropolitan growth,' U.S. Department of Transportation, Office of University Research, Washington D.C.

Carlino, G.A and Mills, E.S (1987) 'The determinants of county growth', Journal of Regional Science, vol. 27. pp. 39-54.

Chernoff, M. (1978) 'Density as a determinant of highway impacts', Transportation Research Record, 686, pp. 4-9.

Costa, J. D., Elson, R.W., and Martin, R.C. (1987) 'Public capital, regional output and development: some empirical evidence,’ Journal of Regional Science, vol. 27, pp. 419437.

Deno, K.T. (1988) 'The effect of public capital on U.S. manufacturing activity: 1970-1978', Southern Economic Journal, vol. 55, pp. 400-411.

Dodgson, J.S. (1974) 'Motorway investment, industrial transport costs, and sub-regional growth: A case study of M62,' Regional Studies, vol. 8, pp. 75-91. 
Eberts, R.W. (1986) 'Estimating the contribution of urban public infrastructure to regional growth,’ Working Paper 8610, Federal Reserve Bank of Cleveland.

Gaegler A.J., March, J.W., and Weiner, P. (1979) 'Dynamic social and economic effects of the Connecticut Turnpike,’ Transportation Research Record. Vol. 716, pp. 28-32.

Hansen, N.M. (1965) 'Unbalanced growth and regional development,' Western Economic Journal, vol. 4, pp. 3-14.

Hansen, N.M. (1973) The Future of Non-Metropolitan America, Lexington, MA: Lexington Books.

Harris, C.C. (1980) 'New developments and extensions of the multiregional, multi-industry forecasting model,' Journal of Regional Science, vol. 20, pp. 159-71.

Hilewick, C.L, Deak, L.E., and Heinze, E. (1980) 'A simulation of communication and transportation investments,' Growth and Change, vol. 11, pp. 26 - 38.

Humphrey, C.R. and Sell, R.R. (1975) 'The impact of controlled access highways on population growth in Pennsylvania nonmetropolitan communities, 1940-1970', Rural Sociology, vol. 42, pp. 332-43.

Isserman, A. M., Rephann, T.J. and Sorenson, D.J. (1989) 'Highways and rural development: Results from quasi-experimental approaches’, West Virginia University, Regional Research Institute Working Paper 8907.

Kilkenny, M. (1998) 'Transport costs and rural development', Journal of Regional Science vol. 38, issue. 2, pp. $293-312$.

Lichter, D.T. and Fuguitt, G.V. (1980) 'Demographic response to transportation innovation: the case of the interstate highway,' Social Forces, vol. 59, pp. 492-511. 
Mikelbank, B.A. and Jackson, R.W. (1999) 'Equity vs. efficiency: Public capital investment in Ohio, 1988-1992,' Professional Geographer, vol. 51, pp., 196-209. , (2000) 'The role of space in public capital research,' International Regional Science Review, vol. 23, no. 3, pp., 235-258.

Miller, J.P. (1979) 'Interstate highways and job growth in nonmetropolitan areas: A reassessment,' Transportation Journal, vol. 19, pp. 78-81.

Moomaw, R.L, Mullen, J.K. and Williams, M (1995) 'The interregional impact of infrastructure capital,' Southern Economic Journal, vol. 61, pp., 830-845.

Munnell, A.H. (1990) 'How does public infrastructure affect regional economic performance,’ New England Economic Review September-October: 11 - 32.

Yilmaz, S., Haynes, K.E., and Dinc, M. (2002) 'Geographic and network neighbors: Spillover effects of telecommunications infrastructure,' Journal of Regional Science, vol. 42, no.2, pp. 339-60. 


\section{Chapter 5}

\section{Summary and Concluding Remarks}




\subsection{Concluding Remarks and Future Research}

The three essays in this dissertation consider different aspects of public highway infrastructure's geo-economic impact on the Appalachian Region. All three essays use spatial econometric methodology to address the spatial interdependence that underlies the economic fundamentals of geographically proximate areas. Spatial models give adequate consideration to interactions of actors in space and spatial interdependence. They should, therefore, yield more conclusive and complete evidence of the effectiveness of expensive highway projects on regional economic growth.

The first essay measures the distance decay in the impact of highway access. OLS results indicate that the farther away an Appalachian population center is from an ADHS corridor or an Interstate, the lower the road infrastructure's impact on the county's employment. The impact is not significant beyond six miles. In rugged, mountainous Appalachia, however, six miles is considerable distance. By mapping the residuals of employment growth from the OLS model (Figure 2.3), we detect evidence of spatial clustering in the employment growth process. The OLS model over-predicts employment growth for most of northeastern Appalachia (some north-central counties of Pennsylvania and the lower tier of New York counties) and central Appalachia (some counties of Virginia and West Virginia), with evidence of some clustering. It under-predicts employment growth in southeastern Appalachia. In states such as Alabama, the distribution is random, indicating only a limited spatial autocorrelation effect.

A Moran's I test on the OLS model indicates the presence of a spatial pattern in the growth process. After conducting the required tests, the spatial autoregressive model was selected as the appropriate model. The positive and highly significant coefficient of 
the spatially-weighted dependent variable (W_EMPGR) implies that when employment growth increases by 1 percent, about a tenth of that could be attributed to the spatial spillovers from neighboring counties. A map of the spatial lag model residuals (Figure 2.4) shows that the spatial patterns of employment growth are no longer as evident as in the OLS case. Clusters give way to randomness across the region, with the exception of Pennsylvania where some clustering still persists. This latter result suggests that the decline of the 'rust belt' is affecting the results. All across Appalachia, growth seems to be under-predicted in counties surrounding large metro areas.

Future extensions of this essay will examine whether highway networks have a larger growth impact whenever a significant network size is achieved (similar to telecommunication networks). This would imply that positive growth effects might be subject to reaching a critical mass in a given region's transportation infrastructure. It is, therefore, necessary to consider the possibility of nonlinearities.

While the first essay addresses the impact of highway access on employment in Appalachia, in the second essay, I examine the extent of spatial externalities of highway investment on output in the presence of spatial autocorrelation. The essay also examines the direction of causality between highway investment and output after accounting for the spatial interdependence among the region's counties. Although some causality studies have focused on public capital and growth, none looked at causality between highways and output in the presence of spatial autocorrelation. I consider a number of spatial models vis-à-vis a standard OLS model and compare the fit. From the model selection analysis, I find that the Spatial Autoregressive Model (SAR) is most appropriate in capturing highway capital's impact on county output. The standard OLS model is subject 
to omitted variable bias in the presence of spatial autocorrelation, which is clearly indicated by the high Moran's I statistic. As for the Spatial Error Model (SEM), it does not find neighbors' highway capital stock or private capital to be significant. The SAR model finds negative and significant coefficient estimates for both private capital and neighbors' highway capital stock. The negative coefficient of neighbors' highway capital stock is an interesting result because it suggests a backwash effect, i.e., highway network expansions in surrounding counties draw productive activity away. Also, the negative private capital coefficient is consistent with the economic shifts occurring in the region where manufacturing industries are on the decline and service sector industries are undergoing rapid growth.

I apply the SAR model in a two-equation framework, one with output and another with highway capital as the dependent variable, to test for causation. I find a positive and significant lagged highway capital coefficient in the output equation, which confirms that highway capital significantly affects output. In the highway equation, lagged output, although positive, is not significant. This would normally indicate that causation runs from highways to output, and not the other way around. Evidence of multicollinearity between public capital and output, however, renders this result inconclusive.

Both equations are characterized by positive and significant spatial spillovers implying that output and highway variables both have spatial processes embedded in them. About one tenth of a percent increase in a county's output (or, highway capital) can be attributed to the spatial diffusion of output (or, highway capital) from surrounding counties. 
In the future, the two-equation SAR methodology used in this essay for the Appalachian Region counties could be extended to include all U.S. counties for a more comprehensive analysis. As it is, studies on regional highway effectiveness present only a partial picture since inter-regional effects are ignored. The larger and more diverse sample might also help to overcome the multicollinearity in the causation analysis.

In the third and final essay, I look at the differential impact of highway capital on output in economically disparate counties. For Appalachia, highways hold a greater significance due to the isolation of the region and the ruggedness of its terrain. A mile of highway is twice as costly to build in Appalachia as in the rest of the United States. Careful study is, therefore, necessary not only to evaluate the impact of highways on the region as a whole but for a clearer understanding of how individual counties benefit given their existing economic condition.

For the 121 Appalachian counties that are designated as 'distressed' by the ARC, own highway capital is positive and significant at the $5 \%$ level implying that an increase in own highway capital investment will bring about a small but positive change in output. Neighbors' highway capital is positive but we cannot reject the null hypothesis of a zero coefficient. This leads us to conclude that neighbors' highway capital does not have much of an influence for distressed counties. Rather, labor and public capital are the major determinants for increases in output or productive activity. Although not very substantial in magnitude, the positive spillover parameter implies that a county's economic performance is directly affected by that of its neighbors, and vice versa.

The SAR results for the 259 Appalachian counties designated as 'transitional' find own highway capital as one of the major positive influences on output. Neighbors' 
highway capital is negative and significant at the $10 \%$ level, indicating a negative backwash effect, i.e., that highway expansions in surrounding counties can draw economic activity away.

According to the SAR results for the 31 'competitive' counties in the region, the coefficient for own highway capital is not significant indicating that if a sizeable highway network is already present in a county at the time of new highway capital injection, the additional highway capital does not significantly contribute to regional output. Neighbors' highway capital is negative and significant at the 5\% level implying that neighbors' highway capital investment draws output away from own county. The spillover process is no longer evident in the competitive counties. A Moran's I test on the standard OLS model does not reject the null hypothesis of no spatial autocorrelation for the competitive counties. Like the SAR results, the OLS estimates also indicate that adding more highway capital does not significantly impact output in these counties that have already reached a level of economic prosperity. Neighbors' highway expansions, however, do seem to draw productive activity away from them.

Using the SAR model wherever a spatial process is evident yields lower coefficient estimates for all variables in the model indicating that the omitted variable type bias has been corrected. We also have a definite idea about the strength and direction of the transmission/diffusion of output's impact across counties, i.e., through space. I find that the largest employment effects for federal highway grants are in regions that previously experienced low growth and distressed areas. My results have a direct relevance for regional transportation policy because they provide additional evidence 
that, although expensive, highway projects positively affect the distressed, nonmetropolitan counties.

In all three cases ('distressed,' 'transitional' and 'competitive'), private capital has a negative sign, but is only significant for the distressed counties. As a future extension of this essay, it would be interesting to examine the industrial mix of each county in this category and test whether our hypothesis regarding increased investment in declining manufacturing industries holds for these counties.

This dissertation considers the role of the ADHS in Appalachian economic performance. Given the rugged terrain characterizing the region, highways and accessibility are key components in any regional development initiative. In this dissertation, I have tried to determine and evaluate the impact of highway infrastructure on employment and output on all regional counties as a whole, as well as examining the difference in highway's impact when the disparity in the economic condition of the regional counties is taken into account. Although no noticeable distance decay is detected in the impact of highway access on county employment once the appropriate spatial model is applied, the findings of this dissertation support the argument that the ADHS has been an effective policy tool in bringing the isolated counties in Appalachia out of poverty and augmenting their economic viability by positively affecting their productive capacity. 